\title{
Parameter induction in continuous univariate distributions: Well-established $G$ families
}

\author{
MUHAMMAD H. TAHIR ${ }^{1}$ and SARALEES NADARAJAH ${ }^{2}$ \\ ${ }^{1}$ Department of Statistics, Baghdad Campus, The Islamia University of Bahawalpur, Bahawalpur 63100, Pakistan \\ ${ }^{2}$ School of Mathematics, University of Manchester, Oxford Road, Manchester, M13 9PL, UK \\ Manuscript received on June 9, 2014; accepted for publication on November 25, 2014
}

\begin{abstract}
The art of parameter(s) induction to the baseline distribution has received a great deal of attention in recent years. The induction of one or more additional shape parameter(s) to the baseline distribution makes the distribution more flexible especially for studying the tail properties. This parameter(s) induction also proved helpful in improving the goodness-of-fit of the proposed generalized family of distributions. There exist many generalized (or generated) $G$ families of continuous univariate distributions since 1985. In this paper, the well-established and widely-accepted $G$ families of distributions like the exponentiated family, Marshall-Olkin extended family, beta-generated family, McDonald-generalized family, Kumaraswamygeneralized family and exponentiated generalized family are discussed. We provide lists of contributed literature on these well-established $G$ families of distributions. Some extended forms of the Marshall-Olkin extended family and Kumaraswamy-generalized family of distributions are proposed.
\end{abstract}

Key words: Beta-distribution, exponentiated family, Kumaraswamy distribution, Marshall-Olkin family, McDonald distribution, reliability properties.

\section{INTRODUCTION}

There has been an increased interest in developing generalized (or generated) $G$ families of distributions by introducing one or more additional shape parameter(s) to the base- line distribution. There is no doubt that the popularity and the use of Euler-beta and -gamma functions in some $G$ families of distributions have attracted the attention of statis- ticians, mathematicians, scientists, engineers, economists, demographers and other applied researchers. One reason might be the computational and analytical facilities available in programming softwares like R (packages), ox5, Python, Matlab, Maple and Mathematica, through which researchers can easily tackle problems involved in computing incomplete- beta and -gamma functions in $G$ families. The second reason is the tail properties of $G$ distributions that can easily be explored by inducting one or more additional shape param- eter(s) to the baseline distribution. Thirdly, this parameter(s) induction has also proved to be helpful in improving the goodness-of-fit of the proposed $G$ family of distributions. Fourthly, $G$ families have the ability to fit skewed data better than existing

AMS (2010): 60E05, 62E10, 62N05

Correspondence to: Saralees Nadarajah

E-mail: mbbsssn2@manchester.ac.uk 
distributions (Pescim et al. 2010). Lastly, the Kumaraswamy $G$ family of distributions can generate effective models for censored data (Cordeiro and de Castro 2011).

There exists many generalized (or generated) $G$ family of distributions like Azzalini's skewed family (Azzalini 1985), Marshall-Olkin extended (MOE) family (Marshall and Olkin 1997), exponentiated family (EF) of distributions (Gupta et al. 1998), beta-generated (beta $G$ ) family (Eugene et al. 2002, Jones 2004a), Ferreira and Steel's skewed family (Ferreira and Steel 2006), transmutated family (Shaw and Buckley 2007, Aryal and Tsokos 2009, 2011), Gupta and Gupta's skewed family (Gupta and Gupta 2008), gamma-generated (GG) families (Zografos and Balakrishnan 2009, Ristić and Balakrishnan 2012, Torabi and Montazari 2012, Nadarajah et al. 2015), transformed-transformer (T-X) family (Alza-Atreh 2011), Kumaraswamy generalized (Kw $G$ ) family (Cordeiro and de Castro 2011, Nadarajah et al. 2012a, Hussain 2013), generalized beta generated (GBG) or McDonald generalized (Mc $G$ ) family (Alexander et al. 2012), beta extended $G$ family (Cordeiro et al. 2012f), Kummer beta generalized family (Pescim et al. 2012), exponentiated transformedtransformer family (ET-X) (Alzaghal et al. 2013), exponentiated generalized (Exp $G$ ) family (Cordeiro et al. 2013e), geometric exponential-Poisson family (Nadarajah et al. 2013a), truncated-exponential skewsymmetric family (Nadarajah et al. 2013c), logistic-generated (Lo $G$ ) family (Torabi and Montazari 2014), Marshall-Olkin extended family (Alshangiti et al. 2014), log-gamma generated (LG $G$ ) families, (Amini et al. 2014), Weibull $G$ family (Bourguignion et al. 2014), Libby-Novick beta family (Cordeiro et al. 2014e), truncated negative-binomial family (Nadarajah et al. 2014a), modified beta $G$ family (Nadarajah et al. 2014b) and exponentiated exponential-Poisson family (Ristić and Nadarajah 2014). These $G$ families of distributions have received a great deal of attention in recent years. In this paper, we discuss the $\mathrm{EF}, \mathrm{MOE}$, beta $G, \mathrm{Mc} G$, $\operatorname{Exp} G$ and $\mathrm{Kw} G$ families of distri- butions and provide additional literature (in chronological order) on these six families of distributions. We also propose some extended forms of the $\mathrm{Kw} G$ families of distributions by introducing one more additional shape parameter(s).

Because of the length of this paper, we have not given details like probabilistic interpretations, analytical properties, estimation methods, simulation algorithms and applications. These details can be obtained from the cited references.

The rest of the paper is organized as follows. In Section 2, the EF of distributions is defined and a list of contributed work is presented. In Section 3, we describe the MOE family and propose one generalized MOE family of distributions. The contributed literature on the MOE family is also presented. In Section 4, the beta $G$ family of distributions is discussed. The contributions to the beta $G$ family of distributions are also listed in this section. In Section 5, the McDonald distributions and Mc $G$ families of distributions are described. The contributed work on Mc $G$ families of distributions is also presented. Section 6 consists of Kumaraswamy distributions and Kw $G$ families of distributions. Some new types of the Kumaraswamy distribution and Kw $G$ families of distributions are proposed. The contributed work on the $\mathrm{Kw} G$ family of distributions is also listed in this section. Section 7 ends the paper with some final remarks.

\section{EXPONENTIATED FAMILY (EF) OF DISTRIBUTIONS}

The genesis of this family can be traced back to the first half of the nineteenth century when Gompertz (1825) and Verhulst $(1838,1845,1847)$ used the cumulative distribution function (cdf) $G(t)=\left(1-\rho e^{-\lambda t}\right)^{\alpha}$ for $t>$ $\lambda^{-1} \log \rho$, where $\rho, \alpha$ and $\lambda$ are positive real numbers. Ahuja and Nash (1967) introduced the generalized Gompertz-Verhulst family of distributions to study growth curve mortality. Gompertz-Verhulst's cdf was the first member of the EF of distributions. The exponentiated exponential (EE) distribution is its particular case 
for $\rho=1$. The properties and estimation methods for parameters of the EF of distributions have been studied by many authors, see Mudholkar and Srivastava (1993), Mudholkar and Hutson (1996), Mudholkar et al. (1995), Gupta and Kundu (1999, 2001a, b, 2007), Pal et al. (2006), Nadarajah and Kotz (2006a), Nadarajah (2011) and Nadarajah et al. (2013b). The EF of distributions is also known as Lehmann alternatives (LAs) (Lehmann 1953) or proportional reversed hazard rate model (PHRM) (see Gupta et al. 1998, Gupta and Gupta 2007, Martínez-Florez et al. 2013), while other authors referred to the EF of distributions as max-stable family (Sarabia and Castillo 2005) and $F^{\alpha}$ - distributions (Gupta et al. 1998, Al-Hussaini, 2010a, b, 2012, Shakil and Ahsanullah 2012, Hamedani 2013 and Ghitany et al. 2013).

In literature there exist four different ways for obtaining the EF of distributions.

\section{LEHMANN ALTERNATIVE 1 (LA1)}

The method of Lehmann alternative 1 (LA1) (due to Lehmann (1953)) has received a great deal of attention in developing the EF of distributions.

If $G(z)$ is the cdf of the baseline distribution, then an EF of distributions is defined by taking the $\alpha$ th-power of $G(z)$ as

$$
F(z)=G(z)^{\alpha},
$$

where $\alpha>0$ is a positive real parameter. The variable $z$ can take any of the form $z=x$ or $z=x-\mu$ or $z=\frac{x-\mu}{\sigma}$ or $z=k\left(\frac{x-\mu}{\sigma}\right)$ or $z=k\left(\frac{x-\mu}{\sigma}\right)^{\frac{1}{\delta}}$. The probability density function (pdf) corresponding to (2.1) is

$$
f(z)=\alpha g(z) G(z)^{\alpha-1}
$$

where $g(z)=d G(z) / d z$ denotes the pdf of $G$. For any lifetime random variable $t$, the survival (reliability) function (sf), $F(t)$, the hazard (failure) rate function (hrf), $h(t)$, the reversed hazard rate function (rhrf), $r(t)$, and the cumulative hazard rate function (chrf), $H(t)$, associated with (2.1) and (2.2) are

$$
\begin{gathered}
\bar{F}(t)=1-G(t)^{\alpha}, \\
h(t)=\alpha g(t) G(t)^{\alpha-1}\left[1-G(t)^{\alpha}\right]^{-1}, \\
r(t)=\alpha g(t) G(t)^{-1},
\end{gathered}
$$

and

$$
H(t)=-\log \left[1-G(t)^{\alpha}\right]
$$

LEHMANN ALTERNATIVE 2 (LA2)

The method of Lehmann alternative 2 (LA2) (due to Lehmann (1953)) has received less attention.

If $G(z)$ is the cdf and $\bar{G}(z)=1-G(z)$ is the sf of the baseline distribution, then an EF of distributions is defined by taking one minus the $\alpha$ th-power of $\bar{G}(z)$ as

$$
F(z)=1-[\bar{G}(z)]^{\alpha},
$$

where $\alpha$ is a positive real parameter. The LA2 cdf may also be written as

The pdf corresponding to $(2.3)$ is

$$
F(z)=1-[1-G(z)]^{\alpha} .
$$

$$
f(z)=\alpha g(z)[1-G(z)]^{\alpha-1}
$$


For any lifetime random variable $t$, the sf, hrf, rhrf and chrf associated with (2.3) and (2.4) are

$$
\begin{gathered}
\bar{F}(t)=[1-G(t)]^{\alpha}, \\
h(t)=\alpha g(t)[1-G(t)]^{-1}, \\
r(t)=\alpha g(t)[1-G(t)]^{\alpha-1}\left\{1-[1-G(t)]^{\alpha}\right\}^{-1},
\end{gathered}
$$

and

$$
H(t)=-\alpha \log [1-G(t)] .
$$

Nadarajah and Kotz (2003, 2006a), Nadarajah (2006) and Rao et al. (2013) used the LA2 approach for introducing exponentiated Fréchet, exponentiated Gumbel and exponen- tiated log-logistic distributions. For more applications of the LA2 approach, the reader is referred to Abd-Elfattah and Omima (2009), AbdElfattah et al. (2010), Rao et al. (2012, 2013), and Al-Nasser and Al-Omari (2013).

USING TRANSFORMATION $z=\log (x), x>0$

Nadarajah (2005a) developed exponentiated distributions by applying the transformation $z=\log (x)$ to (2.3). The cdf, pdf and the hrf of the exponentiated distribution are

and

$$
\begin{gathered}
F(x)=1-\left[1-G\left(e^{x}\right)\right]^{\alpha}, \\
f(x)=a e^{x} g\left(e^{x}\right)\left[1-G\left(e^{x}\right)\right]^{\alpha-1}
\end{gathered}
$$

$$
h(x)=a e^{x} g\left(e^{x}\right)\left[1-G\left(e^{x}\right)\right]^{-1} .
$$

USING TRANSFORMATION $z=-\log (x), x>0$

Nadarajah (2005b) developed exponentiated distributions by applying the transformation $z=-\log (x)$ to $(2.3)$. The cdf, pdf and the hrf of the exponentiated distribution are

\begin{tabular}{|c|c|c|c|}
\hline & Pioneer year & Distribution & Author(s) \\
\hline \multirow[t]{5}{*}{1} & 1967 & Exponentiated exponential distribution & Ahuja and Nash (1967) \\
\hline & & & Gupta et al. (1998) \\
\hline & & & Gupta and Kundu (1999, 2001a, b, 2007) \\
\hline & & & Nadarajah (2011) \\
\hline & & & Venkatesan and Sundaram (2011) \\
\hline \multirow[t]{5}{*}{2} & 1993 & Exponential Weibull distribution & Mudholkar and Srivastava (1993) \\
\hline & & & Mudholkar et al. (1995) \\
\hline & & & Mudholkar and Hutson (1996) \\
\hline & & & Gupta et al. (1998) \\
\hline & & & Jiang and Murthy (1999) \\
\hline
\end{tabular}

$$
\begin{gathered}
F(x)=\left[1-G\left(e^{-x}\right)\right]^{\alpha}, \\
f(x)=a e^{-x} g\left(e^{-x}\right)\left[1-G\left(e^{-x}\right)\right]^{\alpha-1}
\end{gathered}
$$

and

$$
h(x)=a e^{-x} g\left(e^{-x}\right)\left[1-G\left(e^{-x}\right)\right]^{\alpha-1}\left\{1-\left[1-G\left(e^{-x}\right)\right]^{\alpha}\right\}^{-1} .
$$

A list of papers on the EF of distributions is presented in Table I.

TABLE I

Contributed work on the EF of distributions. 
TABLE I (continuation)

\begin{tabular}{|c|c|c|c|}
\hline \multicolumn{2}{|c|}{ S.No. Pioneer year } & \multirow[t]{2}{*}{ Distribution } & \multirow{2}{*}{$\begin{array}{l}\text { Author(s) } \\
\text { Nassar and Eissa (2003) }\end{array}$} \\
\hline & & & \\
\hline & & & Choudhury (2005) \\
\hline & & & Nadarajah and Gupta (2005) \\
\hline & & & Singh et al. (2005) \\
\hline & & & Pal et al. (2006) \\
\hline & & & Ahmed et al. (2008) \\
\hline & & & Saleem and Abo-Kasem (2011) \\
\hline & & & Mazucheli et al. (2012) \\
\hline & & & Qian (2012) \\
\hline & & & Barrios and Dios (2012) \\
\hline & & & Nadarajah et al. (2013b) \\
\hline \multirow[t]{4}{*}{3} & 1998 & Exponentiated gamma distribution & Gupta et al. (1998) \\
\hline & & & Nadarajah and Kotz (2006a) \\
\hline & & & Nadarajah and Gupta (2007) \\
\hline & & & Shawky and Bakoban $(2008,2009,2012)$ \\
\hline \multirow[t]{4}{*}{4} & 1998 & Exponentiated Pareto distribution & Gupta et al. (1998) \\
\hline & & & Nadarajah (2005a) \\
\hline & & & Shawky and Abu-Zinadah (2009) \\
\hline & & & Afify (2010) \\
\hline \multirow[t]{6}{*}{5} & 2001 & Exponentiated Rayleigh distribution & Surles and Padgett $(1998,2001,2005)$ \\
\hline & & & Raqab (1998) \\
\hline & & & Kundu and Raqab (2005) \\
\hline & & & Raqab and Kundu (2006) \\
\hline & & & Raqab and Madi $(2009,2011)$ \\
\hline & & & Abd-Elfattah (2011) \\
\hline \multirow[t]{7}{*}{6} & 2003 & Exponentiated Fréchet distribution & Nadarajah and Kotz (2003) \\
\hline & & & Nadarajah and Kotz (2006a) \\
\hline & & & Abd-Elfattah and Omima (2009) \\
\hline & & & Abd-Elfattah et al. (2010) \\
\hline & & & Jamjoom and Al-Saiary (2012) \\
\hline & & & Al-Nasser and Al-Omari (2013) \\
\hline & & & Marwa et al. (2013) \\
\hline 7 & 2004 & Exponentiated generalized Pareto distribution & Adeyemi and Adebanji (2004) \\
\hline 8 & 2005 & Exponentiated beta distribution & Nadarajah (2005b) \\
\hline 9 & 2006 & Exponentiated generalized extreme value distribution & Adeyemi and Adebanji (2006) \\
\hline \multirow[t]{3}{*}{10} & 2006 & Exponentiated log-logistic distribution & Rosaiah et al. (2006) \\
\hline & & & Aslam and Jun (2010) \\
\hline & & & Rao et al. $(2012,2013)$ \\
\hline \multirow[t]{5}{*}{11} & 2006 & Exponentiated Gumbel distribution & Nadarajah (2006) \\
\hline & & & Nadarajah and Kotz (2006a) \\
\hline & & & Shirke and Kakade (2007) \\
\hline & & & Kakade et al. (2008) \\
\hline & & & Persson and Rydén (2010) \\
\hline \multirow[t]{2}{*}{12} & 2006 & Exponentiated log-normal distribution & Shirke and Kakade (2006) \\
\hline & & & Raja and Mir (2011) \\
\hline \multirow[t]{2}{*}{13} & 2008 & Exponential modified Weibull distribution & Carrasco et al. (2008) \\
\hline & & & Elbatal (2011) \\
\hline 14 & 2009 & Exponentiated extreme value distribution & Cho et al. (2009) \\
\hline 15 & 2011 & Exponentiated Lindley distribution & Nadarajah et al. (2011) \\
\hline 16 & 2011 & Extended generalized exponential distribution & Kundu and Gupta (2011) \\
\hline
\end{tabular}


TABLE I (continuation)

\begin{tabular}{llll}
\hline S.No. Pioneer year & Distribution & Author(s) \\
\hline 17 & 2011 & Exponentiated Burr XII distribution & $\begin{array}{l}\text { Al-Hussaini and Hussein (2011a, b) } \\
\text { Maswadah (2013) }\end{array}$ \\
18 & 2011 & Exponentiated generalized gamma distribution & Cordeiro et al. (2011a) \\
19 & 2011 & Exponentiated generalized inverse Gaussian distribution & Lemonte and Cordeiro (2011) \\
20 & 2012 & Exponentiated inverted Weibull distribution & Flaih et al. (2012) \\
& & & Kim et al. (2012) \\
& & & Hassan (2013) \\
21 & 2012 & Exponentiated Kumaraswamy distribution & Aljuaid (2013) \\
22 & 2012 & Exponentiated Lomax distribution & Kumar (2012) \\
23 & 2012 & Exponentiated Gompertz distribution & Abdul-Moniem and Abdel-Hameed (2012) \\
24 & 2013 & Exponentiated modified Weibull extension distribution & Sl-Gohary (2012) \\
25 & 2013 & Exponentiated generalized linear exponential distribution and Apaloo (2013) & Sarhan et al. (2013) \\
26 & 2013 & Exponentiated Dagum distribution & Khan (2013) \\
27 & 2013 & Exponentiated sinh Cauchy distribution & Cooray (2013) \\
28 & 2015 & Exponentiated geometric distribution & Chakraborty and Gupta (2015)
\end{tabular}

\section{MARSHALL-OLKIN EXTENDED (MOE) FAMILY OF DISTRIBUTIONS}

Marshall and Olkin (1997) proposed a flexible semi-parametric family of distributions and defined a new sf $\bar{F}^{M O}(x)$ by introducing an additional parameter $\alpha>0$. Marshall and Olkin (1997) called $\alpha$ a tilt parameter and interpreted $\alpha$ in terms of the behavior of the hrfs of $\bar{F}^{M O}$ and $G$. Their ratio is increasing in $t$ for $\alpha \geq$ 1 and decreasing in $t$ for $0<\alpha<1$. Nanda and Das (2012) reinterpreted $\alpha$ as a tilt parameter since the hrf of the new family is shifted below $(\alpha \geq 1)$ or above $(0<\alpha \leq 1)$ the hrf of the underlying distribution. Specifically, for all $t \geq 0, h^{M O}(t) \leq h(t)$ when $\alpha \geq 1$, and $h^{M O}(t) \geq h(t)$ when $0<\alpha \leq 1$, where $h^{M O}(t)$ and $h(t)$ are the hrfs of the MOE and baseline distributions.

For any baseline pdf $g(t)$, cdf $G(t)=P(T \leq t)$ and $\operatorname{sf} \bar{G}(t)=P(T>t)$ of the baseline distribution, the sf $\bar{F}^{M O}(t)$ of the MOE family of distributions is defined by

$$
\bar{F}^{M O}(t)=\frac{a \bar{G}(t)}{1-\bar{a} \bar{G}(t)}=\frac{a \bar{G}(t)}{G(t)+a \bar{G}(t)} \quad \text { or } \quad \frac{a[1-G(t)]}{a+\bar{a} \bar{G}(t)},
$$

where $-\infty<t<\infty, \alpha>0$ and $\bar{a}=1-\alpha$. The cdf and pdf associated with (3.1) are

$$
F^{M O}(t)=\frac{\bar{G}(t)}{1-\bar{a} \bar{G}(t)}=\frac{\bar{G}(t)}{G(t)+\bar{a} G(t)} \quad \text { or } \quad \frac{1-G(t)}{a+\bar{a} G(t)}
$$

and

$$
f^{M O}(t)=\frac{a g(t)}{[1-\bar{a} \bar{G}(t)]^{2}} \quad \text { or } \quad \frac{a g(t)}{[a+\bar{a} G(t)]^{2}}
$$

where $-\infty<\mathrm{t}<\infty, \alpha>0$ and $\bar{a}=1-\alpha$. If $\alpha=1$, then we have $\bar{F}^{M O}(t)=\bar{G}(t)$. Other reliability measures like the hrf, rhrf and chrf associated with (3.1) are

$$
h^{M O}(t)=\frac{f^{M O}(t)}{\bar{F}^{M O}(t)}=\frac{g(t)}{\bar{G}(t)} \frac{1}{[1-\bar{a} \bar{G}(t)]}=\frac{h(t)}{1-\bar{a} \bar{G}(t)} \quad \text { or } \quad \frac{h(t)}{a+\bar{a} G(t)},
$$




$$
r^{M O}(t)=\frac{f^{M O}(t)}{F^{M O}(t)}=a \frac{g(t)}{\bar{G}(t)} \frac{1}{[1-\bar{a} \bar{G}(t)]}=\frac{a h(t)}{1-\bar{a} \bar{G}(t)} \quad \text { or } \quad \frac{a h(t)}{a+\bar{a} G(t)}
$$

and

$$
H^{M O}(t)=-\log \left[\frac{a \bar{G}(t)}{1-\bar{a} \bar{G}(t)}\right] \text { or } \quad-\log \left\{\frac{a[1-G(t)]}{a+\bar{a} G(t)}\right\},
$$

where $h(t)$ is the hrf of the baseline distribution.

Note that if we define

$$
\bar{F}^{M O}(t)=\frac{\bar{G}(t)}{1-\bar{a} \bar{G}(t)}
$$

then

$$
F^{M O}(t)=\frac{a \bar{G}(t)}{1-\bar{a} \bar{G}(t)} \quad \text { and } \quad f^{M O}(t)=\frac{g(t)}{[1-\bar{a} \bar{G}(t)]^{2}},
$$

For more general results on the MOE family of distributions, the reader is referred to Barakat et al. (2009), Jose (2011), Krishna (2011), Barreto-Souza et al. (2013) and Cordeiro et al. (2014c).

\section{EXISTING GENERALIZED MOE FAMILY OF DISTRIBUTIONS}

In this section, we describe existing generalized Marshall-Olkin families of distributions.

Jayakumar and Mathew (2008) proposed a generalization of the Marshall and Olkin (1997) family of distributions (by using the LA1 approach) as

$$
\bar{F}^{G M O}(t)=\left[\frac{a \bar{G}(t)}{1-\bar{a} \bar{G}(t)}\right]^{\theta},
$$

where $-\infty<t<\infty, \alpha>0$, and $\theta>0$ is an additional shape parameter. When $\theta=1, \bar{F}^{G M O}(t)=\bar{F}^{M O}(t)$. The cdf and the pdf associated with (3.2) are

$$
F^{G M O}(t)=1-\left[\frac{a \bar{G}(t)}{1-\bar{a} \bar{G}(t)}\right]^{\theta},
$$

and

$$
f^{G M O}(t)=\theta\left[\frac{a \bar{G}(t)}{1-\bar{a} \bar{G}(t)}\right]^{\theta-1}\left\{\frac{a g(t)]}{[1-\bar{a} \bar{G}(t)]^{2}}\right\} .
$$

Other reliability measures like the hrf, rhrf and chrf associated with (3.2) are

and

$$
\begin{gathered}
h^{G M O}(t)=\theta \frac{g(t)}{\bar{G}(t)} \frac{1}{1-\bar{a} \bar{G}(t)}=\theta h(t) \frac{1}{1-\bar{a} \bar{G}(t)}, \text { or } \frac{\theta h(t)}{a+\bar{a} G(t)}, \\
r^{G M O}(t)=\frac{\theta a^{\theta} g(t) G(t)^{\theta-1}}{[1-\bar{a} \bar{G}(t)]^{\theta}-a^{\theta} G(t)^{\theta}},
\end{gathered}
$$

$$
H^{G M O}(t)=-\log \left\{1-\left[\frac{a \bar{G}(t)]}{[1-\bar{a} \bar{G}(t)]}\right]^{\theta}\right\} \text {, }
$$

where $h(t)$ is the hrf of the baseline distribution. 
A NEW GENERALIZED MOE FAMILY OF DistribUtions

Here, we propose another generalization of the Marshall and Olkin (1997) family of distributions. Using the LA2 approach to the sf of the MOE family of distributions, we obtain

$$
\bar{F}^{G 2 M O}(t)=1-\left[1-\frac{a \bar{G}(t)}{1-\bar{a} \bar{G}(t)}\right]^{\theta},
$$

where $-\infty<t<\infty, \alpha>0$, and $\theta>0$ is the additional shape parameter. When $\theta=1, \bar{F}^{G 2 M O}(\mathrm{t})=\bar{F}^{M O}(\mathrm{t})$. The cdf and the pdf associated with (3.3) are

and

$$
F^{G 2 M O}(t)=\left[1-\frac{a \bar{G}(t)}{1-\bar{a} \bar{G}(t)}\right]^{\theta},
$$

$$
f^{G 2 M O}(t)=\theta\left[1-\frac{a \bar{G}(t)}{1-\bar{a} \bar{G}(t)}\right]^{\theta-1}\left\{\frac{a g(x)}{[1-\bar{a} \bar{G}(t)]^{2}}\right\} .
$$

After simplification, the above pdf can be rewritten as

$$
f^{G 2 M O}(t)=\frac{\theta a g(t) G(t)^{\theta-1}}{1-\bar{a} \bar{G}(t)} \text { or } \frac{\theta a g(t) G(t)^{\theta-1}}{a+\bar{a} G(t)} .
$$

Other reliability measures like the hrf, rhrf and chrf associated with (3.3) are

$$
\begin{gathered}
h^{G 2 M O}(t)=\frac{\theta a g(t) G(t)^{\theta-1}}{[a+\bar{a} G(t)]^{\theta+1}}\left\{1-\left[1-\frac{a \bar{G}(t)}{[1-\bar{a} \bar{G}(t)]}\right]^{\theta}\right\}^{-1}, \\
r^{G 2 M O}(t)=\theta a \frac{g(t)}{G(t)} \frac{1}{a+\bar{a} G(t)}=\frac{\theta a r(t)}{a+\bar{a} G(t)},
\end{gathered}
$$

and

$$
H^{G 2 M O}(t)=-\log \left\{1-\left[1-\frac{a \bar{G}(t)}{[1-\bar{a} \bar{G}(t)]}\right]^{\theta}\right\},
$$

where $r(t)$ is the rhrf of the baseline distribution.

The construction in (3.3) is similar to that due to Jayakumar and Mathew (2008). But there is an important distinction. Suppose that a system consists of $\theta$ independent components. Suppose too that each component has a lifetime with the sf given by $\alpha \bar{G}(t) /[1-\bar{a} \bar{G}(t)]$. Then (3.2) is the sf of the minimum of the lifetimes and (3.3) is the sf of the maximum of the lifetimes. So, (3.2) can be used to model the minimum of the lifetimes and (3.3) can be used to model the maximum of the lifetimes.

\section{SEMI-TyPE PROCESSES BASED ON CHARACTERISTIC FUNCTION}

In this section, we briefly discuss semi-Pareto, semi-Burr, semi-Laplace, semi-logistic and semi-Weibull distributions based on the characteristic function (cf) $\psi(t)$ of the baseline distribution. The concept of semitype distributions arose from the minification process. Tavares (1980) defined a minification process as observations in a process generated by

$$
X_{n}=k \min \left(X_{n-1}, \epsilon_{n}\right),
$$

where $n \geq 1, k>1$ is a constant and $\left\{\epsilon_{n}\right\}$ is an innovation process of independent and identically distributed random variables. Here, $\left\{X_{n}\right\}$ is called the first order autoregressive AR(1) minification process. There exists many modified minification processes. 
Linnik (1963) introduced the $\alpha$-Laplace distribution, a symmetric distribution defined on $(-\infty, \infty)$. For $\alpha=2$, the Linnik distribution reduces to the Laplace distribution. Pillai (1985) generalized the Linnik distribution and introduced the semi- $\alpha$-Laplace distribution.

Yeh et al. (1988) modified (3.4) and introduced the first auto-regressive Pareto minification process having Pareto marginals. Arnold and Robertson (1989) introduced minification processes with logistic marginals. Pillai (1991) and Pillai et al. (1995) introduced semi-Pareto minification processes. Balakrishna (1998) investigated some properties and estimated the unknown parameters of Pillai's semi-Pareto minification process.

Pillai (1985) proposed the semi- $\alpha$ Laplace distribution. Its sf is

$$
\bar{F}^{S \operatorname{Lap}}(t)=\frac{1}{1+\psi(t)}
$$

where $\psi(t)$ satisfies the functional equation

$$
\psi(t)=\frac{1}{p} \psi\left(t p^{1 / a}\right),
$$

where $\alpha>0$ and $0<p<1$. The solution of (3.5) is $\psi(t)=|t|^{\alpha} \eta(t)$, where $\eta(t)$ is periodic in $\log |t|$. In the particular case $\eta(t)=c$, the semi- $\alpha$-Laplace distribution reduces to the Linnik distribution.

A random variable $T$ is said to have the semi-Pareto distribution if its $\mathrm{sf}$ is

$$
\bar{F}^{S P}(t)=\frac{1}{1+\psi(t)},
$$

where $t>0$ and $\psi(t)$ satisfies the functional equation

$$
\psi(t)=\frac{1}{p} \psi\left(p^{1 / \gamma}(t)\right)
$$

where $0<p<1, t>0$ and $\gamma>0$. The solution of (3.6) is $\psi(t)=t^{\gamma} \eta(t)$, where $\eta(t)$ is periodic in $\log t$ with period $\left(\frac{-2 \pi \gamma}{\log p}\right)$. Further details are in Pillai (1991) and Pillai et al. (1995).

If $\psi(t)=t^{\gamma}$ (that is for $\eta(t)=1$ ), we obtain the semi-Pareto distribution of type III having the sf

$$
\bar{F}^{S P 3}(t)=\frac{1}{1+t^{\gamma}},
$$

where $t>0$ and $\gamma>0$. For details, see Chrapek et al. (1996), Balakrishna (1998) and Cifarelli et al. (2010).

A random variable $T$ is said to have the semi-Burr distribution if its $\mathrm{sf}$ is

$$
\bar{F}^{S B}(t)=\left[\frac{1}{1+\psi(t)}\right]^{\beta},
$$

where $t>0, \beta>0$ and $\psi(t)$ satisfies the same functional as (3.6).

Cifarelli et al. (2010) expressed the sf of the semi-Burr distribution as

$$
\bar{F}^{S B}(t)=\frac{1}{[1+\psi(t)]^{b+1}},
$$

where $\psi(t)$ satisfies the same functional as (3.6) and $b>0$.

According to Arnold (1992) and Jayakumar and Mathew (2005), a random variable $T$ is said to have the semi-logistic distribution if its $\mathrm{sf}$ is 


$$
\bar{F}^{S L}(t)=\frac{1}{1+\psi(t)}
$$

where $\psi(t)$ is a nondecreasing and right-continuous function satisfying

$$
\psi(t)=\frac{1}{p} \psi\left(t+\frac{1}{\sigma} \log p\right),
$$

where $0<p<1, t>0$, and $\sigma>0$.

According to Jose (1994) and Thomas and Jose (2005), a random variable $T$ is said to have the semi-Weibull distribution if its sf is

$$
\bar{F}^{S W}(t)=\exp [-\psi(t)],
$$

where $\psi(t)$ satisfies the functional equation

$$
p \psi(t)=\psi\left(p^{1 / \gamma}(t)\right)
$$

where $\gamma>0$ and $0<p<1$. Note that (3.8) yields the iterative solution

$$
p^{n} \psi(t)=\psi\left(p^{n / \gamma}(t)\right)
$$

Solving (3.8), we have $\psi(t)=t^{\gamma} h(t)$, where $h(t)$ is periodic in $\log t$ with period $\left(\frac{-2 \pi \gamma}{\log p}\right)$.

More details are in Thomas and Jose (2005).

SEMI-TYPE MARSHALL-OLKIN Distributions BASED ON CHARACTERISTIC FUnCTION

Using (3.1), various authors have proposed Marshall-Olkin semi-type distributions from the baseline cf $\psi(t)$.

Alice and Jose (2003) introduced the Marshall-Olkin semi-Pareto (MOSP) distribution with sf

$$
\bar{F}^{M O S P 3}(t)=\frac{1}{1+\frac{1}{a} \psi(t)},
$$

and established geometric extreme stability. Thomas and Jose (2005) and Alice and Jose (2005b) introduced the Marshall-Olkin semi-Weibull distribution with sf

$$
\bar{F}^{M O S W}(t)=\frac{a}{e^{\psi(t)}-(1-a)},
$$

where $t>0$ and $\alpha>0$. Jayakumar and Mathew (2008) proposed the Marshall-Olkin semi-Burr (GMOSB) distribution as that defined by the $\mathrm{sf}$

$$
\bar{F}^{G M O S B}(t)=\left[\frac{a}{a+\psi(t)}\right]^{\beta}=\left[\frac{1}{1+\frac{1}{a} \psi(t)}\right]^{\beta}=\left[\bar{F}^{M O S P 3}(t)\right]^{\beta},
$$

where $\alpha>0, \beta>0$ and $\psi(t)$ satisfies the same functional as (3.7).

If $0<\alpha<1$ and $\varphi(t)$ is a valid $\mathrm{cf}$ then

$$
\psi(\varphi(t))=\frac{a \varphi(t)}{1-(1-a) \varphi(t)}
$$

is also a valid cf. Using this fact, Krishna and Jose (2011) defined the Marshall-Olkin generalized asymmetric Laplace distribution as that having the $\mathrm{cf}$ 


$$
\psi(t)=\frac{a}{\left(1-\frac{i t}{\lambda_{1}}\right)^{\beta 1}\left(1+\frac{i t}{\lambda_{2}}\right)^{\beta 2}+a-1},
$$

where $i=\sqrt{-1}, 0<\alpha<1, \lambda_{1}>0, \lambda_{2}>0, \beta_{1}>0$ and $\beta_{2}>0$. George and George (2013) defined the Marshall-Olkin Esscher transformed Laplace distribution as that having the $\mathrm{cf}$

$$
\psi(t)=\left[1+\frac{1}{a}\left(\frac{t^{2}}{1-\theta^{2}}-\frac{2 i t \theta}{1-\theta^{2}}\right)\right]^{-1}=\left\{1+\frac{1}{\lambda^{2}}\left[t^{2}-2 i t \theta\right]\right\}^{-1},
$$

where $0<\alpha \leq 1,|\theta|<1, \lambda=\sqrt{a\left(1-\theta^{2}\right)}, k=\frac{\lambda}{\theta+\sqrt{\lambda+\theta^{2}}}, \lambda>0$ and $k>0$. Jose and Uma (2009) defined the Marshall-Olkin Linnik and Mittag-Leffler distributions as those having the cfs

and

$$
\psi(t)=\frac{\beta}{\left(1+|t|^{a}\right)^{v}+\beta-1}
$$

$$
\psi(t)=\frac{\beta}{\beta-s^{a}}
$$

respectively, where $v>0,0<\alpha \leq 2$, and $\beta>0$.

\begin{tabular}{|c|c|c|c|}
\hline S.No. & Pioneer year & Distribution & Author(s) \\
\hline \multirow[t]{10}{*}{1} & 1997 & MOE exponential distribution & Marshall and Olkin (1997) \\
\hline & & & Alice and Jose (2004b) \\
\hline & & & Parikh et al. (2008) \\
\hline & & & Salah et al. (2009) \\
\hline & & & Bdair (2011) \\
\hline & & & Gopal and Damodaran (2011) \\
\hline & & & Krishna (2011) \\
\hline & & & Rao et al. (2011) \\
\hline & & & Salah (2012) \\
\hline & & & Pushkarna et al. (2013) \\
\hline \multirow[t]{9}{*}{2} & 1997 & MOE Weibull distribution & Marshall and Olkin (1997) \\
\hline & & & Jose and Alice (2001) \\
\hline & & & Hirose (2002) \\
\hline & & & Ghitany et al. (2005) \\
\hline & & & Zhang and Xie (2007) \\
\hline & & & Caroni (2010) \\
\hline & & & Srivastava and Kumar (2011) \\
\hline & & & Athar et al. (2012) \\
\hline & & & Cordeiro and Lemonte (2013) \\
\hline 3 & 2003 & MOE Pareto-III distribution & Alice and Jose (2003) \\
\hline 4 & 2003 & MOE Pareto-III distribution & Alice and Jose (2003) \\
\hline \multirow[t]{2}{*}{5} & 2004 & MOE Pareto-I distribution & Alice and Jose (2004a) \\
\hline & & & Ghitany (2005) \\
\hline \multirow[t]{2}{*}{6} & 2005 & MOE logistic distribution & Alice and Jose (2005a) \\
\hline & & & Kumar (2013) \\
\hline 7 & 2005 & MO semi-logistic distribution & Alice and Jose (2005a) \\
\hline
\end{tabular}

A list of papers on the MOE family is presented in Table II.

TABLE II

Contributed work on the MOE family of distributions. 
TABLE II (continuation)

\begin{tabular}{|c|c|c|c|}
\hline S.No. & Pioneer year & Distribution & Author(s) \\
\hline \multirow[t]{2}{*}{8} & 2005 & MO semi-Weibull distribution & Alice and Jose (2005b) \\
\hline & & & Thomas and Jose (2005) \\
\hline \multirow[t]{3}{*}{9} & 2005 & MOE Fréchet distribution & Jose and Alice (2005) \\
\hline & & & Krishna (2011) \\
\hline & & & Krishna et al. (2013) \\
\hline \multirow[t]{2}{*}{10} & 2007 & MOE Lomax distribution & Ghitany et al. (2007) \\
\hline & & & Gupta et al. (2010) \\
\hline 11 & 2007 & MOE linear failure rate distribution & Ghitany and Kotz (2007) \\
\hline \multirow[t]{2}{*}{12} & 2007 & MOE gamma distribution & Ristić et al. (2007) \\
\hline & & & Jose (2009) \\
\hline \multirow[t]{2}{*}{13} & 2008 & MOE q-Weibull distribution & Naik et al. (2008) \\
\hline & & & Jose et al. (2010) \\
\hline \multirow[t]{2}{*}{14} & 2008 & MOE Burr distribution & Jayakumar and Mathew (2008) \\
\hline & & & El-Bassiouny and Abdo (2010) \\
\hline 15 & 2008 & MOE semi-Burr distribution $\dagger$ & Jayakumar and Mathew (2008) \\
\hline 16 & 2008 & MOE semi-Pareto III distribution $\dagger$ & Jayakumar and Mathew (2008) \\
\hline 17 & 2009 & MOE Linnik distribution $\uparrow$ & Jose and Uma (2009) \\
\hline 18 & 2009 & MOE Mittag-Leffler distribution $\dagger$ & Jose and Uma (2009) \\
\hline 19 & 2009 & MOE beta distribution & Jose et al. (2009) \\
\hline \multirow[t]{2}{*}{20} & 2011 & MOE uniform distribution & Krishna (2011) \\
\hline & & & Jose and Krishna (2011) \\
\hline 21 & 2011 & MOE Gumbel distribution & Jose (2011) \\
\hline \multirow[t]{2}{*}{22} & 2011 & $\begin{array}{l}\text { MOE generalized asymmetric Laplace } \\
\text { distribution } \dagger\end{array}$ & Krishna (2011) \\
\hline & & & Krishna and Jose (2011) \\
\hline 24 & 2013 & MOE Zipf distribution & P'erez-Casany and Casellas (2013) \\
\hline 25 & 2013 & MOE power log-normal distribution & Gui (2013a) \\
\hline 26 & 2013 & MOE log-logistic distribution & Gui (2013b) \\
\hline 27 & 2013 & MOE quasi-Lindley distribution & Gui (2013c) \\
\hline 28 & 2013 & $\begin{array}{l}\text { MOE Esscher transformed Laplace } \\
\text { distribution } \dagger\end{array}$ & George and George (2013) \\
\hline
\end{tabular}

\section{BETA DISTRIBUTIONS AND EXISTING BETA $G$ FAMILIES OF DISTRIBUTIONS}

Consider the cdf of a beta random variable of type 1 with two shape parameters $a$ and $b$ given by

$$
F^{B 1}(x)=P(X \leq x)=I_{x}(a, b)=\frac{B_{x}(a, b)}{B(a, b)}=\frac{1}{B(a, b)} \int_{0}^{x} x^{a-1}(1-x)^{b-1} d x,
$$

where $a>0, b>0, x \in(0,1), \mathrm{B}_{t}(a, b)=\int_{0}^{t} t^{a-1}(1-t)^{b-1} d t$ is the incomplete beta function, $\operatorname{It}(a, b)$ is the incomplete beta function ratio and $B(a, b)=\int_{0}^{1} t^{a-1}(1-t)^{b-1} d t=\frac{\Gamma(a) \Gamma(b)}{\Gamma(a+b)}$ is the beta function. The pdf corresponding to (4.1) is

where $a>0, b>0, x \in(0,1)$.

$$
f^{B 1}(x)=\frac{1}{B(a, b)} x^{a-1}(1-x)^{b-1}
$$


Similarly, the cdf of a beta random variable of type 2 with parameters $a$ and $b$ is

$$
F^{B 2}(y)=P\left(Y \leq \mathrm{y}=I 2_{y}(a, b)=\frac{B 2_{y}(a, b)}{B 2(a, b)}=\frac{1}{B 2(a, b)} \int_{0}^{y} \frac{y^{a-1}}{(1+y)^{a+b}} d y,\right.
$$

where $a>0, b>0, y>0, B 2_{t}(a, b) \int_{0}^{t} t^{a-1}(1+t)^{-(a+b)} d t$ is the incomplete beta function, $I 2_{t}(a, b)$ is the incomplete beta function ratio and $B 2(a, b)=\int_{0}^{\infty} t^{a-1}(1+t)^{-(a+b)} d t=\frac{\Gamma(a) \Gamma(b)}{\Gamma(a+b)}$ is the beta function. The pdf corresponding to (4.2) is

$$
f^{B 2}(y),=\frac{1}{B 2(a, b)} \frac{y^{a-1}}{(1+y)^{(a+b)}},
$$

where $a>0, b>0$, and $y>0$. The beta type 2 distribution is also known as inverted beta distribution as it can be obtained from (4.1) by the transformation $Y=\frac{X}{1-X}$.

Cardeño et al. (2005) introduced the beta type 3 distribution by transforming $Z=\frac{Y}{2-Y}$ in (4.1). The cdf of a beta random variable of type 3 with parameters $a$ and $b$ is

$$
F^{B 3}(z)=P(Z \leq z)=13_{z}(a, b)=\frac{B 3_{z}(a, b)}{B 3(a, b)}=\frac{1}{B 3(a, b)} \int_{0}^{z} \frac{z^{a-1}(1-z)^{b-1}}{(1+z)^{(a+b)}} d z
$$

where $a>0, b>0, z \in(0,1), B 3_{t}(a, b)=\int_{0}^{t} t^{a-1}(1-t)^{b-1}(1+t)^{-(a+b)} d t$ is the incomplete beta function, $13 t(a, b)$ is the incomplete beta function ratio and $B 3(a, b)=\int_{0}^{1} t^{a-1}(1-t)^{b-1}(1+t)^{-(a+b)} d t=\frac{\Gamma(a) \Gamma(b)}{\Gamma(a+b)}$ is the beta function. The pdf corresponding to (4.3) is

$$
f^{B 3}(z)=\frac{2^{a}}{B 3(a, b)} \frac{z^{a-1}(1-z)^{b-1}}{(1+z)^{(a+b)}}
$$

where $a>0, b>0$, and $z \in(0,1)$.

Eugene et al. (2002) and Jones (2004a) replaced the upper limit $x$ of the integral in (4.1) with $G(x)$. The resulting cdf of beta $G$ family of distributions is

$$
F^{B G}(x)=I_{G(x)}(a, b)=\frac{B_{G(x)}(a, b)}{B(a, b)}=\frac{1}{B(a, b)} \int_{0}^{G(x)} \omega^{a-1}(1-\omega)^{b-1} d \omega .
$$

The pdf corresponding to (4.4) is

$$
f^{B G}(x)=\frac{1}{B(a, b)} g(x) G(x)^{a-1}[1-G(x)]^{b-1},
$$

where $g(x)=d G(x) / d x$ denotes the pdf. The beta $G$ family of distributions is also known as the beta logit family. For any lifetime random variable $t$, the sf, hrf, rhrf and chrf associated with (4.4) and (4.5) are

$$
\begin{gathered}
\bar{F}(t)=1-I_{G(x)}(a, b)=\frac{B(a, b)-B_{G(t)}(a, b)}{B(a, b)}, \\
h(t)=\frac{g(t) G(t)^{a-1}[1-G(t)]^{b-1}}{B(a, b)\left[I_{\mathrm{G}(t)}(a, b)\right]}=\frac{g(t) G(t)^{a-1}[1-G(t)]^{b-1}}{B_{\mathrm{G}(t)}(a, b)},
\end{gathered}
$$




$$
r(t)=\frac{g(t) G(t)^{a-1}[1-G(t)]^{b-1}}{B(a, b)\left[1-I_{\mathrm{G}(t)}(a, b)\right]}=\frac{g(t) G(t)^{a-1}[1-G(t)]^{b-1}}{\left[B(a, b)-B_{\mathrm{G}(t)}(a, b)\right]}
$$

and

$$
H(t)=-\log \left[\frac{B(a, b)-B_{G(t)}(a, b)}{B(a, b)}\right] .
$$

A list of papers on the beta $G$ family of distributions is given in Table III.

TABLE III

\begin{tabular}{|c|c|c|c|}
\hline S.No. & Pioneer year & Distribution & Author(s) \\
\hline \multirow[t]{7}{*}{1} & 2002 & Beta normal distribution & Eugene et al. (2002) \\
\hline & & & Famoye et al. (2002) \\
\hline & & & Eugene (2004) \\
\hline & & & Famoye et al. (2004) \\
\hline & & & Gupta and Nadarajah (2004) \\
\hline & & & Jones (2004b) \\
\hline & & & Rěgo et al. (2012) \\
\hline \multirow[t]{2}{*}{2} & 2003 & Beta exponential distribution & Maynard (2003) \\
\hline & & & Nadarajah and Kotz (2006b) \\
\hline 3 & 2004 & Beta gamma distribution & Kong (2004), Kong et al. (2007) \\
\hline 4 & 2004 & Beta Gumbel distribution & Nadarajah and Kotz (2004) \\
\hline \multirow[t]{2}{*}{5} & 2004 & Beta Fréchet distribution & Nadarajah and Gupta (2004) \\
\hline & & & Barreto-Souza et al. (2011) \\
\hline \multirow[t]{6}{*}{6} & 2005 & Beta Weibull distribution & Famoye et al. (2005) \\
\hline & & & Lee et al. (2007) \\
\hline & & & Zografos (2008) \\
\hline & & & Cordeiro et al. $(2011 b, c)$ \\
\hline & & & Sun (2011), Mdziniso (2012) \\
\hline & & & Mahmoud and Mandouh (2012a, b, c) \\
\hline 7 & 2006 & Beta Bessel distribution & Gupta and Nadarajah (2006) \\
\hline 8 & 2008 & Beta Pareto distribution & Akinsete et al. (2008) \\
\hline 9 & 2008 & Beta Rayleigh distribution & Akinsete and Lowe (2009) \\
\hline \multirow[t]{2}{*}{10} & 2008 & Beta Laplace distribution & Kozubowski and Nadarajah (2008) \\
\hline & & & Cordeiro and Lemonte (2011a) \\
\hline \multirow[t]{2}{*}{11} & 2009 & Beta generalized logistic-IV distribution & Morais (2009) \\
\hline & & & Morais et al. (2013) \\
\hline \multirow[t]{2}{*}{12} & 2010 & Beta modified Weibull distribution & Silva et al. (2010) \\
\hline & & & Nadarajah et al. (2012b) \\
\hline 13 & 2010 & Beta generalized half-normal distribution & Pescim et al. (2010) \\
\hline 14 & 2010 & Beta generalized exponential distribution & Barreto-Souza et al. (2010) \\
\hline 15 & 2010 & Beta Maxwell distribution & Amusan (2010) \\
\hline 16 & 2010 & Beta hyperbolic secant distribution & Fischer and Vaughan (2010) \\
\hline \multirow[t]{2}{*}{17} & 2010 & Beta inverse Weibull distribution & Kersey (2010) \\
\hline & & & Hanook et al. (2013) \\
\hline \multirow[t]{2}{*}{18} & 2011 & Beta Cauchy distribution & Alshawarbeh (2011) \\
\hline & & & Alshawarbeh et al. (2012) \\
\hline 19 & 2011 & Beta half-Cauchy distribution & Cordeiro and Lemonte (2011b) \\
\hline 20 & 2011 & Beta Burr XII distribution & Paranaíba et al. (2011) \\
\hline 21 & 2011 & Beta generalized Pareto distribution & Mahmoudi(2011) \\
\hline
\end{tabular}

Contributed work on the beta $G$ family of distributions. 
TABLE III (continuation)

\begin{tabular}{|c|c|c|c|}
\hline S.No. & Pioneer year & Distribution & Author(s) \\
\hline & & & Nassar and Nada (2011) \\
\hline 22 & 2011 & Beta Birnbaum-Sanders distribution & Cordeiro and Lemonte (2011c) \\
\hline 23 & 2012 & Beta skew-normal distribution & Mameli (2012) \\
\hline 24 & 2012 & Beta exponential-geometric distribution & Bidram (2012) \\
\hline 25 & 2012 & Beta Moyal distribution & Cordeiro et al. (2012d) \\
\hline 26 & 2012 & Beta generalized Weibull distribution & Singla et al. (2012) \\
\hline 27 & 2012 & Beta exponentiated Pareto distribution & Zea et al. (2012) \\
\hline 28 & 2012 & Beta power distribution & Cordeiro and Brito (2012) \\
\hline 29 & 2012 & Beta linear failure rate distribution & Jafari and Mahmoudi (2012) \\
\hline 30 & 2012 & Beta extended Weibull distribution & Cordeiro et al. (2012f) \\
\hline 31 & 2012 & Beta truncated Pareto distribution & Lourenzutti et al. (2012) \\
\hline 32 & 2013 & Beta Weibull-geometric distribution & Cordeiro et al. (2013f) \\
\hline & & & Bidram et al. (2013) \\
\hline 33 & 2013 & Beta generalized gamma distribution & Cordeiro et al. (2013a) \\
\hline 34 & 2013 & Beta log-normal distribution & Castellars et al. (2013) \\
\hline 35 & 2013 & Beta generalized Rayleigh distribution & Cordeiro et al. (2013b) \\
\hline 36 & 2013 & Beta generalized logistic distribution & Morais et al. (2013) \\
\hline 37 & 2013 & Beta exponentiated Weibull distribution & Cordeiro et al. (2013c) \\
\hline 38 & 2013 & Beta Nakagami distribution & Shittu and Adepoju (2013) \\
\hline 39 & 2013 & Beta Burr III distribution & Gomes et al. (2013) \\
\hline 40 & 2013 & Beta Dagum distribution & Domma and Condino (2013) \\
\hline 41 & 2013 & Beta Stoppa distribution & Mansoor (2013) \\
\hline 42 & 2013 & Beta inverse Rayleigh distribution & Le ao et al. (2013) \\
\hline 43 & 2014 & Beta generalized inverse Weibull distribution & Baharith et al. (2014) \\
\hline 44 & 2014 & Beta extended half-normal distribution & Cordeiro et al. (2014f) \\
\hline 45 & 2014 & Beta log-logistic distribution & Lemonte (2014) \\
\hline
\end{tabular}

\section{MCDONALD DISTRIBUTIONS AND MCDONALD G FAMILIES OF DISTRIBUTIONS}

\section{MCDONALD TYPE DisTRIBUTIONS}

McDonald (1984) replaced the upper limit $x$ of the integral in (4.1) with $x^{c}$, where $c$ is an additional (third) shape parameter. The resulting cdf of the McDonald type (Mc) distribution is

$$
F(x)=I_{x^{c}}(a, b)=\frac{B_{x^{c}}(a, b)}{B(a, b)}=\frac{1}{B(a, b)} \int_{0}^{x^{c}} x^{a-1}(1-x)^{b-1} d x,
$$

where $a>0, b>0$ and $c>0$ are the three shape parameters. The Mc distribution includes as special cases the beta type 1 distribution $(c=1)$ and the Kumaraswamy distribution $(a=1)$. The pdf corresponding to (5.1) is

$$
f(x)=\frac{c}{B(a, b)} x^{a c-1}\left(1-x^{c}\right)^{b-1},
$$

where $0<x<1$.

\section{EXISTING MCDONALD G FAMILY OF DisTRIBUTIONS}

For any baseline cdf $G(x)$, Alexander et al. (2012) replaced the upper limit $x^{c}$ of the integral in (5.1) with $G(x)^{c}$. Lemonte and Cordeiro (2013) stated that this simple transformation facilitates the computation of several properties of the $G$ family of distributions. 
The resulting $\operatorname{cdf} F(x)$ of the Mc-generalized family of distributions (Mc $G$ ) is

$$
F(x)=I_{G(x)^{c}}(a, b)=\frac{B_{G(x)^{c}}(a, b)}{B(a, b)}=\frac{1}{B(a, b)} \int_{0}^{G(x)^{c}} \omega^{a-1}(1-\omega)^{b-1} d \omega,
$$

where $I_{G(x)^{c}}(a, b)$ denotes the incomplete beta function ratio. The pdf corresponding to (5.2) is

$$
f(x)=\frac{c}{B(a, b)} g(x) G(x)^{a c-1}\left[1-G(x)^{c}\right]^{b-1},
$$

where $a>0, b>0$ and $c>0$ are the three shape parameters. For a lifetime random variable $t$, the sf, hrf, rhrf and chrf associated with (5.2) and (5.3) are

$$
\begin{gathered}
\bar{F}(t)=1-I_{G(t)^{c}}(a, b)=\frac{B(a, b)-B_{G(t) c}(a, b)}{B(a, b)}, \\
h(t)=\frac{c g(t) G(t)^{a c-1}\left[1-G(x)^{c}\right]^{b-1}}{B(a, b)\left[I_{G(t)^{c}}(a, b)\right]}=\frac{c g(t) G(t)^{a c-1}\left[1-G(t)^{c}\right]^{b-1}}{B_{G(t)^{c}}(a, b)}, \\
r(t)=\frac{c g(t) G(t)^{a c-1}\left[1-G(t)^{c}\right]^{b-1}}{B(a, b)\left[1-I_{G(t)^{c}}(a, b)\right]}=\frac{c g(t) G(t)^{a c-1}\left[1-G(t)^{c}\right]^{b-1}}{\left[B(a, b)-B_{G(t)^{c}}(a, b)\right]},
\end{gathered}
$$

and

$$
H(t)=-\log \left[\frac{B(a, b)-B_{G(t)^{c}}(a, b)}{B(a, b)}\right] .
$$

\section{NOTES ON EXISTING MC $G$ FAMILIES OF DISTRIBUTIONS}

The three shape parameters $a, b$ and $c$ introduce skewness, kurtosis, and vary tail weights. The parameters control skewness and kurtosis through altering the tail entropy (Alexander et al. 2012). They also control skewness and kurtosis through adding entropy to the center of the baseline distribution (Alexander et al. 2012). Cordeiro et al. (2014b) mentioned that $a$ and $b$ are skewness parameters that control relative tail weights but not the peak, but $c$ provides the control over the peak.

Alexander et al. (2012), Marciano et al. (2012), Cordeiro and Lemonte (2012, 2014), Cordeiro et al. (2012a, b, 2013d, 2014b), Lemonte and Cordeiro (2013) and Gomes et al. (2013a) used Mc $G$ distributions for developing McDonald normal, McDonald (extended) exponential, McDonald gamma, McDonald inverted beta, McDonald arcsine, McDonald Weibull, McDonald Birnbaum-Sanders (fatigue life), McDonald Lomax, McDonald Burr XII and McDonald Burr III distributions. These authors believe that the Mc $G$ family of distributions can fit skew data better than existing distributions. The Mc $G$ family of distributions is most applicable when $G(x)$ and $g(x)$ take simple analytical forms.

The Mc $G$ family of distributions reduces to the beta $G$ family of distribution for $c=1$ and to the $\mathrm{Kw} G$ family of distribution for $a=c$. Further, the Mc $G$ family of distributions for $G(x)=x$ contains as particular cases the beta type 1 distribution $(c=1)$ and the Kumaraswamy distribution $(a=c)$.

Zografos (2011) studied a family of distributions based on McDonald and Xu (1995)'s generalized beta distribution. This family was called the family of generalized beta generated (GBG) distributions.

A list of papers on the Mc $G$ family of distributions is given in Table IV. 
TABLE IV

Contributed work on the Mc $G$ family of distributions.

\begin{tabular}{cccc}
\hline S.No. & Pioneer year & Distribution & Author(s) \\
\hline 1 & 2010 & McDonald Kumaraswamy distribution & Carrasco et al. (2010) \\
2 & 2012 & McDonald exponential distribution & Cordeiro et al. (2012f) \\
3 & 2012 & McDonald gamma distribution & Marciano et al. (2012) \\
4 & 2012 & McDonald inverted beta distribution & Cordeiro and Lemonte (2012) \\
5 & 2012 & McDonald normal distribution & Cordeiro et al. (2012a) \\
6 & 2012 & McDonald extended exponential distribution & Cordeiro et al. (2012b) \\
7 & 2013 & McDonald Burr XII distribution & Gomes et al. (2015) \\
8 & 2013 & McDonald Burr III distribution & Gomes et al. (2015) \\
9 & 2013 & McDonald Lomax distribution & Lemonte and Cordeiro (2013) \\
10 & 2013 & McDonald Birnbaum-Sanders distribution & Cordeiro et al. (2013d) \\
11 & 2013 & McDonald Fisk (log-logistic) distribution & Zubair (2013) \\
12 & 2013 & McDonald Dagum distribution & Rajasooriya (2013) \\
& & & Oluyede and Rajasooriya (2013) \\
13 & 2013 & McDonald modified Weibull distribution & Merovci and Elbatal (2013) \\
14 & 2014 & McDonald arcsine distribution & Cordeiro and Lemonte (2014) \\
15 & 2014 & McDonald Weibull distribution & Cordeiro et al. (2014b) \\
16 & 2015 & McDonlad Burr distribution & Cordeiro et al. (In press) \\
\hline
\end{tabular}

KUMARASWAMY DisTRIBUTIONS AND KUMARASWAMY G FAMILIES OF DISTRIBUTIONS

Kumaraswamy (1980) argued that the beta distribution does not fairly fit hydrological random variables like rainfall, daily stream flow, etc. Jones (2009) commented that "beta distribution is fairly tractable, but in some ways not fabulously so. In particular its distribution function is an incomplete beta function ratio and its quantile function the inverse thereof'. The Kumaraswamy (Kw) distribution is relatively much appreciated in comparison to the beta distribution, and has a simple form which can be unimodal, increasing, decreasing or constant, depending on the parameter values.

In this section, we give functional forms of $\mathrm{Kw}$ distributions. We also propose Kumaraswamy generalized families of distributions.

\section{EXISTING KUMARASWAMY DISTRIBUTIONS}

The Kw distribution has the cdf and the pdf specified by

$$
F(x)=1-\left(1-x^{a}\right)^{b},
$$

and

$$
f(x)=a b x^{a-1}\left(1-x^{a}\right)^{b-1},
$$

respectively, where $0<x<1$ and $a>0, b>0$ are both shape parameters.

EXISTING KUMARASWAMY G FAMILY OF DisTRIBUTIONS

For a baseline cdf $G(x)$ with pdf $g(x)$, Cordeiro and de Castro (2011) defined the Kw $G$ distribution specified by the cdf and the pdf

$$
F(x)=1-\left[1-G(x)^{a}\right]^{b},
$$

and 


$$
f(x)=a b g(x) \mathrm{G}(x)^{a-1}\left[1-G(x)^{a}\right]^{b-1},
$$

where $x>0, g(x)=\mathrm{d} G(x)=d x$ and $a>0, b>0$ are shape parameters in addition to those in the baseline distribution. They partly govern skewness and vary tail weights. For a lifetime random variable $t$, the sf, hrf, rhrf and chrf associated with (6.3) and (6.4) are

$$
\begin{gathered}
\bar{F}(t)=\left[1-G(x)^{a}\right]^{b}, \\
h(t)=a b g(t) G(t)^{a-1}\left[1-G(t)^{a}\right]^{-1} \\
r(t)=a b g(t) G(t)^{a-1}\left[1-G(t)^{a}\right]^{b-1}\left\{1-\left[1-G(x)^{a}\right]^{b}\right\}^{-1},
\end{gathered}
$$

and

$$
H(t)=-b \log \left[1-G(x)^{a}\right]
$$

\section{NOTES ON KUMARASWAMY $G$ FAMILIES OF DistribUTIONS}

Equations (6.3) and (6.4) do not involve any special function like the beta function, incomplete beta function, incomplete beta ratio, gamma function, incomplete gamma func- tion or the incomplete gamma ratio. Therefore, the generalization in (6.3) and (6.4) is computationally more efficient compared to beta $G$ and Mc $G$ families of distributions.

The Kw $G$ families of distributions are more flexible than the baseline distribution in the sense that the families allow for greater flexibility of tail properties. Their second benefit is their ability to fit skew data that cannot be properly fitted by existing distributions.

\section{NOTES ON KUMARASWAMY G FAMILIES OF DISTRIBUTIONS}

Equations (6.3) and (6.4) do not involve any special function like the beta function, incomplete beta function, incomplete beta ratio, gamma function, incomplete gamma func- tion or the incomplete gamma ratio. Therefore, the generalization in (6.3) and (6.4) is computationally more efficient compared to beta $G$ and Mc $G$ families of distributions.

The Kw $G$ families of distributions are more flexible than the baseline distribution in the sense that the families allow for greater flexibility of tail properties. Their second benefit is their ability to fit skew data that cannot be properly fitted by existing distributions.

A list of papers on the Kw $G$ family of distributions is given in Table V.

TABLE V

Contributed work on Kumaraswamy $G$ family of distributions.

\begin{tabular}{cccc}
\hline S.No. & Pioneer year & Distribution & Author(s) \\
\hline 1 & 2010 & Kumaraswamy Weibull distribution & Cordeiro et al. (2010) \\
2 & 2011 & Kumaraswamy generalized gamma distribution & de Pascoa et al. (2011) \\
3 & 2011 & Kumaraswamy skew-normal distribution & Kazemi et al. (2011) \\
& & & Mameli (2012) \\
& & & Mameli and Musio (2013) \\
4 & 2011 & Kumaraswamy Gumbel minimum distribution & El-Sherpieny and Ahmed (2011) \\
5 & 2012 & Kumaraswamy log-logistic distribution & Muthulakshmi and Selvi (2013) \\
& 2012 & Kumaraswamy Gumbel distribution & Cordeiro et al. (2012c) \\
7 & 2012 & Kumaraswamy Birnbaum-Sanders distribution & Saulo et al. (2012) \\
\hline
\end{tabular}


TABLE V (continuation)

\begin{tabular}{cccc}
\hline S.No. & Pioneer year & Distribution & Author(s) \\
\hline 8 & 2012 & Kumaraswamy generalized half-normal distribution & Cordeiro et al. (2012e) \\
9 & 2012 & Kumaraswamy inverse Weibull distribution & Shahbaz et al. (2012) \\
10 & 2012 & Kumaraswamy normal distribution & Correa et al. (2012) \\
11 & 2012 & Kumaraswamy generalized inverse Weibull distribution & Yang (2012) \\
12 & 2013 & Kumaraswamy Pareto distribution & Bourguignion et al. (2013) \\
13 & 2013 & Kumaraswamy generalized Pareto distribution & Nadarajah and Eljabri (2013) \\
14 & 2013 & Kumaraswamy Burr XII distribution & Paranaíba et al. (2013) \\
15 & 2013 & Kumaraswamy generalized extreme value distribution & Eljabri (2013) \\
16 & 2013 & Kumaraswamy linear exponential distribution & Elbatal (2013a) \\
17 & 2013 & Kumaraswamy generalized linear failure rate distribution & Elbatal (2013b) \\
18 & 2013 & Kumaraswamy exponentiated Pareto distribution & Elbatal (2013c) \\
19 & 2013 & Kumaraswamy Lomax distribution & Shams (2013) \\
20 & 2013 & Exponentiated Fisk (log-logistic) distribution & Zubair (2013) \\
21 & 2014 & Exponentiated generalized Burr III distribution & Zubair (2013) \\
22 & 2014 & Kumaraswamy modified Weibull distribution & Cordeiro et al. (2014d) \\
23 & 2014 & Kumaraswamy generalized Rayleigh distribution & Gomes et al. (2014) \\
\hline
\end{tabular}

NEW KUMARASWAMY TYPE DISTRIBUTION

Setting $X=1-Y$ in (6.1) and (6.2), we obtain a distribution specified by the cdf and the pdf

$$
F(x)=1-\left[1-(1-x)^{a}\right]^{b}
$$

and

$$
f(x)=a b(1-x)^{a-1}\left[1-(1-x)^{a}\right]^{b-1},
$$

where $0<x<1$ and $a>0, b>0$ are the shape parameters.

OTHER KW G FAMILIES OF DISTRIBUTIONS

Replacing $x$ with $G(x)$ in (6.5), we obtain a Kw $G$ distribution specified by the cdf

$$
F(x)=1-\left\{1-[1-G(x)]^{a}\right\}^{b},
$$

where $a>0$ and $b>0$ are both shape parameters. The pdf corresponding to (6.7) is

$$
f(x)=\operatorname{abg}(x)[1-G(x)]^{a-1}\left\{1-[1-G(x)]^{a}\right\}^{b-1} .
$$

Equations (6.6) and (6.7) are the cdf and the pdf of the $\operatorname{Exp} G$ family of distributions recently proposed by Cordeiro et al. (2013e). For a lifetime random variable $t$, the sf, hrf, rhrf and chrf associated with (6.6) and (6.7) are

$$
\begin{gathered}
\bar{F}(t)=\left\{1-[1-G(t)]^{a}\right\}^{b}, \\
h(t)=a b g(t)[1-G(t)]^{a-1}\left\{1-[1-G(t)]^{a}\right\}^{-1}, \\
r(t)=a b g(t)[1-G(t)]^{a-1}\left\{1-[1-G(t)]^{a}\right\}^{b-1}\left[1-\left\{1-[1-G(t)]^{a}\right\}^{b}\right]^{-1},
\end{gathered}
$$

and

$$
H(t)=-b \log \left\{1-[1-G(t)]^{a}\right\} .
$$




\section{CONCLUSIONS}

We first refer to some important surveys on the developments of continuous univariate distributions: Kotz and Vicari (2005) surveyed the developments in the theory of skewed continuous distributions; Gupta and Kundu (2009) described six different methods for the induction of shape and/or skewness parameter(s) in univariate probability distributions; Chakraborty and Hazarika (2011) surveyed the theoretical developments of the univariate skew-normal distribution, its extensions and generalizations; Lee et al. (2013) surveyed recent methods for generating families of univariate continuous distributions. They discussed five general methods for generating $G$ families of distributions: (1) method for generating skewed distributions, (2) method for adding parameters (e.g., exponentiation), (3) beta $G$, (4) transformed-transformer (T-X) family, and (5) composite method. Recently, Nadarajah (2015a, 2015b) introduced the R package Newdistns which computes the pdf, cdf, quantiles and random numbers for nineteen general families of distributions.

In this paper, we have discussed the well-established and widely used $G$ families of distributions: the EF of distributions, the MOE distributions, the beta $G$ distributions, the $\mathrm{Mc} G$ distributions, the $\mathrm{Kw} G$ distributions and the $\operatorname{Exp} G$ distributions. We have provided exhaustive lists of papers on these families of distributions. We have cited 28 papers on the EF of distributions, 28 papers on the MOE distributions, 45 papers on the beta $G$ distributions, 16 papers on the Mc $G$ distributions, 21 papers on the $\mathrm{Kw} G$ distributions and 2 papers on the Exp $G$ distributions. The literature review in Lee et al. (2013) appears less detailed.

We have introduced several new families of distributions relating to the MOE distribu- tions and the $\mathrm{Kw} G$ distributions. Of course, this is not an attempt to increase the frequency of articles on new families of distributions but rather to effectively explore real life phenom- ena through data sets available from different fields. We have noted that contributors (practitioners) have used different model selection criteria: the maximized $\log$-likelihood $\ell(\widehat{\theta})$, the Akaike Information Criterion (AIC), the Bayesian Information Criterion (BIC), the Consistent Akaike Information Criterion (CAIC), the Hannan-Quinn Information Cri- terion (HQIC), the Cramer-von-Mises $\left(W^{*}\right)$, the Anderson-Darling $\left(A^{*}\right)$, the Wald $(W)$ statistic, the Kolmogorov-Smirnov (K-S) test and graphical inspection of the proximity of histograms to the fitted pdfs.

Tractability and effectiveness for modeling censored data require, among other things, closed form expressions for the cdf. So, the Kw G distributions can be tractable and effective models for censored data. The EF and MOE distributions can also be tractable and effective models for censored data, provided $\mathrm{G}$ is in closed form. However, beta G and Mc G distributions may not be tractable or effective models for censored data since their cdfs involve the incomplete beta function.

It is very appreciating that the contributors have expanded the horizon of applications with efficient statistical modeling. In this regard, the acknowledgements and appreciation go to Professors M. C. Jones, Narayanaswamy Balakrishnan, Kostas Zografos, Felix Famoye, Carl M. -S. Lee, Ramesh C. Gupta, Arjun Kumar Gupta, Rameshwar D. Gupta, Debasis Kundu, Mohamad E. Ghitany, and K. K. Jose. Special acknowledgements and apprecia- tion go to the Brazilian Statisticians Group headed by Professor Gauss M. Cordeiro for introducing the $\operatorname{Mc} G, \operatorname{Kw} G, \operatorname{Exp} G$, beta extended $G$, Weibull $G$ families and exploring their properties. We note that 58 of the listed papers in the References section belong to Professor Cordeiro.

\section{ACKNOWLEDGMENTS}

Both authors would like to thank Professors Felix Famoye, Carl Lee, Kostas Zografos, Miroslav Ristić, Edwin Ortega, Antonio Gomes, Devendra Kumar, Shola Adeyemi, Ibrahim Elbatal and Wenhao Gui for 
sending PDF's of their published work. Both authors would also like to thank the Editor, the Associate Editor and the three referees for carefully reading and for providing comments which greatly improved the paper.

\section{RESUMO}

O método de adicionar parâmetros a uma distribuição especificada tem sido bastante adotado nos últimos anos. A adição de um ou mais parâmetros de forma torna a distribuição gerada mais flexível especialmente no estudo de suas propriedades. Esse método tem se mostrado eficaz, também, na melhoraria das estatísticas de adequação do ajuste da nova distribuição. Desde 1985, muitas famílias de distribuições contínuas geradas por esse método têm sido investigadas. Neste artigo, as famílias geradoras mais conhecidas de distribuições como a família estendida de MarshallOlkin, a família beta, as famílias generalizadas de McDonald e Kumaraswamy e as famílias exponencializadas são discutidas. Apresentam-se as referências mais importantes dessas famílias. Algumas formas mais amplas da família estendida de Marshall-Olkin e da família generalizada de Kumaraswamy são propostas.

Palavras-chave: Distribuição beta, família exponencializada, distribuição de Kumaraswamy, família de MarshallOlkin, distribuição de McDonald, propriedades da confiabilidade.

\section{REFERENCES}

ABD-ElfattaH AM. 2011. Goodness of fit test for the generalized Rayleigh distribution with unknown parameters. J Stat Comput Simul 81: 357-366.

AbD-Elfattah AM, Fergany HA and Omima AM. 2010. Goodness of fit tests for generalized Fréchet distribution. Aust J Basic Appl Sci 4: 286-301.

ABD-ElFATTAH AM AND OMIMA AM. 2009. Estimation of unknown parameters of generalized Fréchet distribution. J Appl Sci Res 5: 1398-1408.

ABdul-Moniem IB AND ABDEL-HAMEEd HF. 2012. On exponentiated Lomax distribution. Int J Math Arch 3: $2144-2150$.

AdEYEMI S AND AdEBANJ AO. 2004. The exponentiated generalized Pareto distribution. Ife J Sci 6: 127-133.

ADEYEMI S AND AdEBANJI AO. 2006. The exponentiated generalized extreme value distribution. J Appl Funct Differ Equ 1: 41-47.

AFIFY WM. 2010. On the estimation of the exponentiated Pareto distribution under different sampling schemes. Stat Methodol 7: $77-83$.

AHMED N, BOKHARI MU, QUADRI SMK AND KHAN MGH. 2008. The exponentiated Weibull distribution software reliability growth model with various testing-efforts and optimal release policy. Int J Qual Reliab Manag 25: 211-235.

AHUJA JC AND NASH SW. 1967. The generalized Gompertz-Verhulst family of distributions. Sankhyā 29: 141-161.

AKinsete A, FAmoye F And LeE C. 2008. The beta-Pareto distribution. Statistics 42: 547-563.

AKInSETE A AND Lowe C. 2009. Beta-Rayleigh distribution in reliability measure. Proc Joint Stat Meet Phys Eng Sci Sect (ASA), p. 3103-3107.

Alexander C, Cordeiro GM, Ortega EMM and Sarabia JM. 2012. Generalized beta-generated distributions. Comput Stat Data Anal 56: 1880-1897.

AL-Hussaini EK. 2010a. On exponentiated distributions: A review. Paper presented at $9^{\text {th }}$ Int Conf Ordered Stat Data Their Applic held at Zagazaig University, Egypt on 11-13 July 2010.

AL-HUSSAINI EK. 2010b. Inference based on censored samples from exponentiated populations. Test 19: 487-513.

AL-HuSSAINI EK. 2012. Composition of cumulative distribution functions. J Stat Theor Appl 11: 323-336.

AL-Hussaini EK AND HusseIn M. 2011a. Estimation using censored data from exponentiated Burr type XII population. Amer Open J Statist 1: 33-45.

AL-HusSAINI EK AND HussEIN M. 2011b. Bayes estimation of future observables from exponentiated Burr type XII population. Amer Open J Statist 1: 24-32.

AL-NASSER AD AND AL-OMARI AI. 2013. Acceptance sampling plan based on truncated life tests for the exponentiated Fréchet distribution. J Statist Manag Sys 16: 13-24.

Alice T AND Jose KK. 2003. Marshall-Olkin Pareto processes. Far East J Theor Stat 9: 117-132.

ALICE T AND Jose KK. 2004a. Marshall-Olkin Pareto distributions and its reliability applications. IAPQR Trans 29: 1-9.

ALICE T AND JoSE KK. 2004b. Marshall-Olkin exponential time series processes. STARS Int J 5: 12-22.

ALICE T AND Jose KK. 2005a. Marshall-Olkin logistic processes. STARS Int J 6: 1-11. 
Alice T AND Jose KK. 2005b. Marshall-Olkin semi-Weibull minification processes. Recent Adv Stat Theor Appl 1: 6-17.

ALJUAID A. 2013. Estimation the parameters of an exponentiated inverted Weibull distribution under type-II censoring. Appl Math Sci 7: 1721-1736

Alshangiti AM, Kayid M and Alarfaj B. 2014. A new family of Marshall-Olkin extended distributions. Jnl Comp Appl Math 271: 369-379.

Alshawarbeh E. 2011. Beta-Cauchy Distribution and Its Application. Ph.D. Thesis, Department of Mathematics, Central Michigan University, Mount Pleasant, Michigan, USA. (Unpublished).

Alshawarbeh E, Lee C and Famoye F. 2012. The beta-Cauchy distribution. J Probab Stat Sci 10: 41-57.

AlzaAtreh A. 2011. A New Method for Generating Families of Continuous Distributions. Ph.D. Thesis, Central Michigan University, Mount Pleasant, Michigan, USA. (Unpublished).

Alzaghal A, LeE C And FAmoye F. 2013. Exponentiated T-X family of distributions with some applications. Int J Statist Probab 2: 31-49.

Amini M, MirMostafaee SMTK and AhMadi J. 2014. Log-gamma-generated families of distribution. Statistics 48: $913-932$.

Amusan GE. 2010. The Beta Maxwell Distribution. M.A. Mathematics Thesis, Department of Mathematics, Marshall University, Huntington, West Virginia, USA. (Unpublished).

ARNOLD BC. 1992. Logistic and semi-logistic processes. J Comput Appl Math 40: 193-149.

ARNOLD BC AND RoBERTSOn CA. 1989. Autoregressive logistic process. J Appl Probab 26: 524-531.

ARYAL GP AND TSOKOS CP. 2009. On the transmuted extreme value distribution with application. Nonlinear Anal 71: 1401-1407.

ARYAL GP AND TsOKOS CP. 2011. Transmuted Weibull distribution: A generalization of the Weibull probability distribution. Eur J Pure Appl Math 4: 89-102.

ASLAM M AND JUN CH. 2010. A double acceptance sampling plan for generalized loglogistic distributions with known shape parameters. J Appl Statist 37: 405-414.

Athar H, NAYABUdDin S AND KhawaJA SK. 2012. Relations for moments of generalized order statistics from Marshall-Olkin extended Weibull distribution and its characterization. ProbStat Forum 5: 127-132.

AZZALINI A. 1985. A class of distributions which includes the normal ones. Scand J Statist 12: 171-178.

Baharith LA, Mousa SA, Atallah MA AND Elgayar SH. 2014. The beta generalized inverse Weibull distribution. British J Math Comput Sci 4: 252-270.

BALAKRISHNA N. 1998. Estimation of semi-Pareto processes. Commun Statist Theor Meth 27: 2307-2323.

BARAKAT HM, GHITANy ME AND AL-Hussaini EK. 2009. Asymptotic distributions of order statistics and record values under the Marshall-Olkin parameterization operation. Commun Statist Theor Meth 38: 2267-2273.

Barreto-Souza W, Cordeiro GM and Simas A. 2011. Some results for beta Fréchet distribution. Commun Statist Theor Meth 40: 798-811.

BARreto-SouZA W, LEMONTE AJ AND CORdeIRo GM. 2013. General results for Marshall and Olkin's family of distributions. An Acad Bras Cienc 85: 3-21.

BARreto-SouZA W, SANTOS AHS AND CORdeIRo GM. 2010. The beta generalized exponential distribution. J Stat Comput Simul 80: $159-172$.

BARRIOS R AND DIOS F. 2012. Exponentiated Weibull distribution family under aperture averaging for Gaussian beam waves. Opt Express 20: 13055-13064.

BDAIR OM. 2011. Different methods of estimation for Marshall-Olkin exponential distribution. J Appl Stat Sci 19: 141-158.

BIDRAM H. 2012. The beta exponential-geometric distribution. Commun Statist Theor Meth 41: 1606-1622.

Bidram H, Behboodian J And TAWHidi M. 2013. The beta Weibull-geometric distribution. J Stat Comput Simul 83: 52-67.

Bourguignion M, Silva MB, Zea LM And Cordeiro GM. 2013. The Kumaraswamy Pareto distribution. J Stat Theor Appl 12: 129-144.

Bourguignion M, Silva RB AND Cordeiro GM. 2014. The Weibull G family of probability distributions. J Data Sci 12: 53-68.

CARDEÑo L, NAGAR DK AND SANCHEZ LE. 2005. Beta type 3 distribution and its multivariate generalization. Tamsui Oxf J Math Sci 21: 225-241.

CARONI C. 2010. Testing for the Marshall-Olkin extended form of Weibull distribution. Stat Pap 51: 325-336.

CArrasco JMF, Ferrari SLP And Cordeiro GM. 2010. A new generalized Kumaraswamy distribution. Available online from http://arxiv.org/abs/1004.0911v1.

CARrasco JMF, ORTEGA EMM AND CORDEIRo GM. 2008. A generalized modified Weibull distribution for lifetime modeling. Comput Stat Data Anal 53: 450-462.

Castellars F, Montenegro LC and Cordeiro GM. 2013. The beta-log-normal distribution. J Stat Comput Simul 83: $203-228$.

CHAKRABORTY S AND GUPTA RD. 2015. Exponentiated geometric distribution: Another generalization of geometric distribution. Commun Statist Theor Meth 44: 1143-1157. 
CHAKRABORTY S AND HAZARIKA PJ. 2011. A survey of the theoretical developments in univariate skew-normal distribution. Assam Stat Rev 25: 41-63.

CHO YS, KANG SB AND HAN JT. 2009. The exponentiated extreme value distribution. J Korean Data Inf Sci Soc 20: 719-731.

Choudhury A. 2005. A simple derivation of moments of the exponentiated Weibull distribution. Metrika 62: 17-22.

Chrapek M, Dudkiewicz J And Dziubdziela W. 1996. On the limit distributions of the kth order statistics for semi-Pareto processes. Appl Math 24: 189-193.

Cifarelli DM, GuPTA RP AND JAYAKUMAR K. 2010. On generalized semi-Pareto and semi-Burr distributions and random coefficient minification processes. Stat Pap 51: 193-208.

COORAY K. 2013. Exponentiated sinh Cauchy distribution. Commun Statist Theor Meth 42: 3838-3852.

CORDEIRO GM AND BRITO RDS. 2012. The beta power distribution. Braz J Probab Statist 26: 88-112.

Cordeiro GM, CAstellares F, Montenegro LC And DE CASTRo M. 2013a. The beta generalized gamma distribution. Statistics 47: 888-900.

Cordeiro GM, Cintra RJ, Rego LC and Ortega EMM. 2012a. The McDonald normal distribution. Pakistan J Statist Oper Res 8: $301-329$

Cordeiro GM, Cristino CT, Hashimoto EM And Ortega EMM. 2013b. The beta generalized Rayleigh distribution with applications to lifetime data. Stat Pap 54: 133-161.

Cordeiro GM AND DE CASTRO M. 2011. A new family of generalized distributions. J Stat Comput Simul 81: 883-893.

Cordeiro GM, Gomes AE AND DA SILVA CQ. 2014a. Another extended Burr III model: Some properties and applications. J Stat Comput Simul 84: 2524-2544.

Cordeiro GM, Gomes AE, Da Silva CQ And OrTega EMM. 2013c. The beta exponentiated Weibull distribution. J Stat Comput Simul 83: 114-138.

Cordeiro GM, Hashimoto EH and Ortega EMM. 2014b. The McDonald Weibull model. Statistics 48: $256-278$.

Cordeiro GM, Hashimoto EH, Ortega EMM and PAscoa MAR. 2012b. The McDonald extended distribution: Properties and applications. AStA Adv Stat Anal 96: 409-433.

Cordeiro GM AND LEMONTE AJ. 2011a. The beta Laplace distribution. Statist Probab Lett 81: 973-982.

CordeIRo GM AND LeMONTE AJ. 2011b. The beta-half-Cauchy distribution. J Probab Statist 2011: 8.

Cordeiro GM AND LEMONTE AJ. 2011c. The $\beta$-Birnbaum-Sanders distribution: An improved distribution for fatigue life modeling. Comput Statist Data Anal 55: 1445-1461.

Cordeiro GM AND LEMONTE AJ. 2012. The McDonald inverted beta distribution. J Franklin Inst 347: 1399-1429.

Cordeiro GM AND Lemonte AJ. 2013. On Marshall-Olkin extended Weibull distribution. Stat Pap 54: 333-353.

Cordeiro GM And Lemonte AJ. 2014. The McDonald arcsine distribution: A new model to proportional data. Statistics 48: $182-199$.

Cordeiro GM, LEMonte AJ AND OrTEGA EMM. 2013d. An extended fatigue life distribution. Statistics 47: 626-653.

Cordeiro GM, Lemonte AJ And OrTega EEM. 2014c. The Marshall-Olkin family of distributions: Mathematical properties and new models. J Stat Theor Pract 8: 343-366.

Cordeiro GM, NADARAJAh S AND OrTega EMM. 2012c. The Kumaraswamy Gumbel distribution. Stat Meth Appl 21: 139-168.

Cordeiro GM, Nobre JS, Pescim RR And OrTega EMM. 2012d. The beta Moyal: A useful skew distribution. Int J Res Rev Appl Sci 10: 171-192.

Cordeiro GM, Ortega EMM AND Da CunHa DCC. 2013e. The exponentiated generalized class of distributions. J Data Sci 11: 1-27.

Cordeiro GM, Ortega EMM, Hamedani GG and Gracia DA. In Press. The McDonald Burr XII model: Properties and applications.

Cordeiro GM, Ortega EMM and Nadarajah S. 2010. The Kumaraswamy Weibull distribution with application to failure data. J Franklin Inst 349: 1174-1197.

Cordeiro GM, ORTEGA EMM AND SILVA GO. 2011a. The exponentiated generalized gamma distribution with application to lifetime data. J Stat Comput Simul 81: 827-842.

Cordeiro GM, OrTEGa EMM AND Silva GO. 2014d. The Kumaraswamy modified Weibull distribution: Theory and applications. J Stat Comput Simul 84: 1387-1411.

Cordeiro GM, Pescim RR And ORTEgA EMM. 2012e. The Kumaraswamy generalized half-normal distribution for skewed positive data. J Data Sci 10: 195-224.

Cordeiro GM, SAntana LH, Ortega EMM And Pescim RR. 2014e. A new family of distributions: Libby-Novick beta. International Journal of Statistics and Probability 3: 63-80.

Cordeiro GM, Silva GO AND OrTega EMM. 2012f. The beta extended Weibull distribution. J Probab Stat Sci 10: 15-40.

Cordeiro GM, Silva GO AND ORTEGA EMM. 2013f. The beta Weibull-geometric distribution. Statistics 47: 817-634.

Cordeiro GM, Silva GO, PESCIM RR AND ORTEGA EMM. 2014f. General properties for the beta extended half-normal distribution. J Stat Comput Simul 84: 881-901. 
CORDEIRO GM, SIMAS AB AND STOŠIC BD. 2011b. Explicit expressions for the moments of the beta Weibull distribution. Available online from http://arxiv.org/abs/0809.1860.

CORDEIRO GM, SiMAS AB AND STOŠIC BD. 2011c. Closed form expressions for moments of the beta Weibull distribution. An Acad Bras Cienc 83: 357-373.

CORrea MA, Nogueira DA AND Ferreira EB. 2012. Kumaraswamy normal and Azzalini's skew normal modeling asymmetry. Sigmae 1: 65-83.

DE PASCOA MAR, ORTEGA EMM AND CORDEIRO GM. 2011. The Kumaraswamy generalized gamma distribution with application in survival analysis. Stat Methodol 8: 411-433.

DE SAntana TVF, ORtega EMM, Cordeiro GM and Silva GO. 2012. The Kumaraswamylog-logistic distribution. J Stat Theor Appl 11: 265-291.

Domma F AND Condino F. 2013. The beta-Dagum distribution. Commun Statist Theor Meth 42: 4070-4090.

EL-BASSIOUNY AH AND ABDo NF. 2010. Reliability properties of seven parameters Burr XII distribution. Comput Meth Sci Tech 16: $127-133$.

EL-Gohary A. 2012. The generalized Gompertz distribution. Appl Math Model 37: 13-24.

EL-SHERPIENY ESA AND AHMED MA. 2011. On the Kumaraswamy-Gumbel distribution. Paper presented at $46^{\text {th }}$ Ann Conf Statist Comput Sci Oper Res, ISSR-Cairo University, Egypt, 26-29 December 2011.

ELBATAL I. 2011. Exponentiated modified Weibull distribution. Econ Qual Control 26: 189-200.

Elbatal I. 2013a. Kumaraswamy linear exponential distribution. Pioneer J Theor Appl Statist 5: 59-73.

ELBATAL I. 2013b. Kumaraswamy generalized linear failure rate distribution. Indian J Comput Appl Math 1: 61-78.

ELBATAL I. 2013c. Kumaraswamy exponentiated Pareto distribution. Econ Qual Control 28: 1-8.

ElJabri SS. 2013. New Statistical Models for Extreme Values. Ph.D. Thesis, Faculty of Engineering and Physical Sciences, University of Manchester, UK. (Unpublished).

Eugene N. 2004. A Generalized Normal Distribution: Properties, Estimation and Applications. Ph.D. Thesis, Central Michigan University, Mount Pleasant, Michigan, USA. (Unpublished).

Eugene N, Lee C And Famoye F. 2002. Beta-normal distribution and its applications. Commun Statist Theor Meth 31: 497-512.

FAmoye F, LeE C And Eugene N. 2002. Beta-normal distribution: Biomodality properties and application. Proc Joint Stat Meet Phys Eng Sci Sect ASA, p. 951-956.

FAmoye F, LeE C AND Eugene N. 2004. Beta-normal distribution: Biomodality properties and application. J Mod Appl Stat Meth 3: $85-103$.

Famoye F, LeE C And Olumolade O. 2005. The beta-Weibull distribution. J Stat Theor Appl 4: 121-136.

FERREIRA JTAS AND STEEL MFJ. 2006. A constructive representation of univariate skewed distributions. J Amer Statist Assoc 100: 823-829.

Fischer M AND VAughan D. 2010. The beta-hyperbolic secant distribution. Austrian J Statist 39: 245-258.

Flaih A, Elsalloukh H, Mendi E and Milanova M. 2012. The exponentiated inverted Weibull distribution. Appl Math Inf Sci 6: $167-171$

GEORGE D AND GEORGE S. 2013. Marshall-Olkin Esscher transformed Laplace distribution and processes. Braz J Probab Statist 27: $162-184$

GHITANY ME. 2005. Marshall-Olkin extended Pareto distribution and its application. Int J Appl Math 18: 17-31.

GHitany ME, Al-Awadhi FA AND AlKhalfan LA. 2007. Marshall-Olkin extended Lomax distribution and its applications to censored data. Commun Statist Theor Meth 36: 1855-1866.

GHITANY ME, AL-HUSSAINI EK AND AL-JARALLAH RA. 2005. Marshall-Olkin extended Weibull distribution and its application to censored data. J Appl Statist 32: 1025-1034.

GHITANY ME, AL-JARALLAH RA AND BALAKRISHNAN N. 2013. On the existence and uniqueness of the MLEs of the parameters of a general class of exponentiated distributions. Statistics 47: 605-612.

GHITANy ME AND KotZ S. 2007. Reliability properties of extended linear failure-rate distributions. Probab Eng Inf Sci 21: 441-450.

Gomes AE, Da Silva CQ And CordeIro GM. 2015. Two extended Burr models: Theory and practice. Commun Statist Theor Meth 44(8): 1706-4734.

Gomes AE, DA SiLVA CQ, CORDEIRo GM AND ORTEGA EMM. 2013. The beta Burr III model for lifetime data. Braz J Probab Statist 27: 502-543.

Gomes AE, Da Silva CQ, Cordeiro GM And OrTega EMM. 2014. A new lifetime model: The Kumaraswamy generalized Rayleigh distribution. J Stat Comput Simul 84: 290-309.

GOMPERTZ B. 1825. On the nature of the function expressive of the law of human mortality, and on a new mode of determining the value of life contingencies. Philos Trans R Soc Lond 115: 513-585.

GOPAL G AND DAMODARAN D. 2011. Software reliability growth models based on Marshall-Olkin generalized exponential families of distributions. Proc IEEE Conf Qual Reliab Bangkok, Thailand on 14-17 September 2011, p. 177-181. 
GuI W. 2013a. A Marshall-Olkin power log-normal distribution and its applications to survival data. Int J Statist Probab 2: 63-72.

GUI W. 2013b. Marshall-Olkin extended log-logistic distribution and its application in minification processes. Appl Math Sci 7: 3947-3961.

GuI W. 2013c. A generalized quasi Lindley distribution in lifetime analysis and its properties. Int J Appl Math Statist 45: 447-459. Gupta AK AND NAdARAJAH S. 2004. On the moments of beta normal distribution. Commun Statist Theor Meth 33: 1-13.

GUPTA AK AND NADARAJAH S. 2006. Beta-Bessel distribution. Int J Math Sci 2006: 14.

GUPTA RC, GHITANY ME AND AL-MUTAIRI DK. 2010. Estimation of reliability from Marshall-Olkin extended Lomax distributions. J Stat Comput Simul 80: 937-947.

GuPTA RC, GuPTA PI AND GuPTA RD. 1998. Modeling failure time data by Lehmann alternatives. Commun Statist Theor Meth 27: 887-904.

GUPTA RC AND GUPTA RD. 2007. Proportional revered hazard rate model and its applications. J Statist Plann Infer 137: $3525-3536$.

GUPTA RD AND GUPTA RC. 2008. Analyzing skewed data by power normal model. Test 17: 197-210.

GUPTA RD AND KUNDU D. 1999. Generalized exponential distribution. Aust N Z J Stat 41: 173-188.

GUPTA RD AND KUNDU D. 2001a. Generalized exponential distribution: An alternative to gamma and Weibull distributions. Biom J 43: 117-130.

GuPTA RD AND Kundu D. 2001b. Generalized exponential distribution: Different methods of estimations. J Stat Comput Simul 69: 315-337.

GUPTA RD AND KUNDU D. 2007. Generalized exponential distribution: Existing results and some recent developments. J Statist Plann Infer 137: 3537-3547.

GUPTA RD AND KUNDU D. 2009. Introduction of shape/skewness parameter(s) in a probability distribution. J Probab Stat Sci 7: 153-171.

HAMEDANi GH. 2013. Characterization of exponentiated distributions. Pakistan J Statist Oper Res 9: 17-24.

Hanook S, Shahbaz MQ, Mohsin M AND Kibria BMG. 2013. A note on beta-inverse-Weibull distribution. Commun Statist Theor Meth 42: 320-335.

HASSAN AM. 2013. On the optimal design of failure step-stress partially accelerated life tests for exponentiated inverted Weibull with censoring. Aust J Basic Appl Sci 7: 97-104.

HIROSE H. 2002. Maximum likelihood parameter estimation in the extended Weibull distribution and its applications to breakdown voltage estimation. IEEE Trans Dielect Elect Insul 9: 524-536.

HuSSAIN MA. 2013. Estimation of $\mathrm{P}(\mathrm{Y}<\mathrm{X})$ for the class of Kumaraswamy G distribution. Aust J Basic Appl Sci 7: $158-169$.

JAFARI AA AND MAHMOUDI E. 2012. Beta-linear failure rate distribution and its application. Available online from http://arxiv.org/ pdf/1212.5615.pdf.

JAMJOOM AA AND AL-SAIARY ZA. 2012. Computing the moments of order statistics from independent non-identically distributed exponentiated Fréchet variables. J Probab Statist 2012: 14.

JAYAKUMAR K AND MATHEW T. 2005. Semi-logistic distributions and processes. Stoch Model Appl 7: 20-32.

JAYAKUMAR KAND MATHEW T. 2008. On a generalization to Marshall-Olkin scheme and its application to Burr type XII distribution. Stat Pap 49: 421-439.

JiANG R AND MURTHY DNP. 1999. The exponentiated Weibull family: A graphica approach. IEEE Trans Reliab 48: 68-72.

JONES MC. 2004a. Families of distributions arising from the distributions of order statistics. Test 13: 1-43.

JONES MC. 2004b. The moments of the beta-normal distribution with integer parameters are the moments of order statistics from the normal distribution (Letter to the editor). Commun Statist Theor Meth 33: 2869-2870.

JONES MC. 2009. Kumaraswamy's distributions: A beta-type distribution with some tractability advantages. Stat Methodol 6: 70-91.

JosE KK. 1994. Some Aspects of Non-Gaussian Auto-Regressive Time Series Modeling. Ph.D. Thesis, University of Kerala, India. (Unpublished).

JosE KK. 2009. Marshall-Olkin gamma distribution and its applications. Proc Natl Workshop on Fract Calc Stat Distn, 25-27 November 2009, CMS Pala Campus, p. 95-106.

JosE KK. 2011. Marshall-Olkin family of distributions and their applications in reliability theory, time series modeling and stressstrength analysis. Proc. ISI $58^{\text {th }}$ World Statist. Congr Int Stat Inst, $21^{\text {st }}-26^{\text {th }}$ August 2011, Dublin, p. 3918-3923.

JosE KK AND ALICE E. 2001. Marshall-Olkin generalized Weibull distributions and applications. STARS Int J 2: 1-8.

Jose KK AND AlicE E. 2005. Marshall-Olkin Family of Distributions: Applications in Time Series Modelling and Reliability. J.C. Publications, Palakkad, India.

Jose KK, JosePh A AND Ristić MM. 2009. A Marshall-Olkin beta distribution and its applications. J Probab Stat Sci 7: $173-186$.

JoSE KK AND KRISHNA E. 2011. Marshall-Olkin extended uniform distribution. ProbStat Forum 4: 78-88.

JoSE KK, NAIK S AND RistiĆ MM. 2010. Marshall-Olkin q-Weibull distribution and max-min processes. Stat Pap 51: 837-851.

Jose KK AND UMA P. 2009. On Marshall-Olkin Mittag-Leffer distributions and processes. Far East J Theor Stat 28:189-199. 
KAKADE CS, SHIRKE DT AND Kundu D. 2008. Inference for $\mathrm{P}(\mathrm{Y}<\mathrm{X})$ in exponentiated Gumbel distribution. J Statist Appl 3: 121-133.

KAZEMI MR, HAGHBIN H AND BEHBOODIAN J. 2011. Another generalization of the skew normal distribution. World Appl Sci J 12: 1034-1039.

KERSEY JX. 2010. Weighted Inverse Weibull and Beta-Inverse Weibull Distribution. M.Sc. Mathematics Thesis, Georgia Southern University, Statesboro, Georgia, USA. (Unpublished).

Khan MZ. 2013. Dagum, Inverse Dagum and Generalized Dagum Income Size Distributions. M.Phil. Thesis, Department of Statistics, The Islamia University of Bahawalpur, Pakistan. (Unpublished).

KIM Y, SEO SI AND KANG SB. 2012. Bayesian estimators using record statistics of exponentiated inverse Weibull distribution. Commun Korean Stat Soc 19: 479-493.

Kong L. 2004. A Study of the Properties, Estimations and Applications for the Beta-Gamma Distribution. Ph.D. Thesis, Central Michigan University, Mount Pleasant, Michigan, USA. (Unpublished).

KONG L, LEE C AND SEPANSKI JH. 2007. On the properties of beta-gamma distribution. J Mod Appl Stat Meth 6: $187-211$.

KOTZ S AND VICARI D. 2005. Survey of developments in the theory of continuous skewed distributions. Metron LXIII: $225-261$.

KOZUBOWSKI TJ AND NADARAJAH S. 2008. The beta-Laplace distribution. J Comput Anal Appl 10: 305-318.

KRISHNA E. 2011. Marshall-Olkin Generalization of Some Distributions and Their Applications. Ph.D. Thesis, Mahatama Ghandi University, Kottayam, Kerala, India. (Unpublished).

KRISHNA E AND JOSE KK. 2011. Marshall-Olkin generalized asymmetric Laplace distributions and processes. Statistica LXXI: 453-467.

KrishnA E, Jose KK AND Ristić MM. 2013. Applications of Marshall-Olkin Fréchet distribution. Commun Statist Simul Comput 42: 76-89.

KUMAR D. 2012. Explicit expressions for the moments of lower generalized order statistics from exponentiated Kumaraswamy distribution and its characterization. J Appl Probab Statist 6: 61-72.

KUMAR D. 2013. Relations for marginal and joint moment generating functions of Marshall-Olkin extended logistic distribution based on lower generalized order statistics and characterization. Amer J Math Manag Sci 32: 19-39.

KUMARASWAMY P. 1980. Generalized probability density-function for double-bounded random processes. J Hydrol 46: 70-88.

KUNDU D AND GUPTA RD. 2011. An extension of the generalized exponential distribution. Stat Methodol 8: 485-496.

Kundu D AND RAQAB MZ. 2005. Generalized Rayleigh distribution: Different methods of estimation. Comput Statist Data Anal 49: $187-200$

LEÃo J, SAUlo H, Bourguignion M, CinTRA R, LÊGO L AND CORDEIRO GM. 2013. On some properties of the beta inverse Rayleigh distribution. Chil J Statist 4: 111-131.

LEE C, FAMOYE F AND AlZAATREH A. 2013. A method for generating families of univariate continuous distributions in the recent decades. WIREs Comput Statist 5: 219-238.

LeE C, Famoye F And Olumolade O. 2007. Beta-Weibull distribution: Some properties and applications to censored data. J Mod Appl Stat Meth 6: 173-186.

LeHMANN EL. 1953. The power of rank tests. Ann Math Statist 24: 23-43.

LEMONTE AJ. 2014. The beta log-logistic distribution. Braz J Probab Statist 28: 313-332.

Lemonte AJ AND CordeIRo GM. 2011. The exponentiated generalized inverse Gaussian distribution. Statist Probab Lett 81: $506-517$.

LEMONTE AJ AND CORDEIRO GM. 2013. An extended Lomax distribution. Statistics 47: 800-816.

LINNIK YV. 1963. Linear forms and statistical criteria. I, II. Trans Math Statist Probab (AMS) 3: 1-90.

Lourenzutti R, Duarte D, Castellares F And AZEVedo M. 2012. The beta truncated Pareto distribution. UFMG, 02-03-2012. Available online from http://hdl.handle.net/1843/BUOS-92FNQK.

Mahmoud MR and Mandouh RM. 2012a. Parameter estimation of beta-Weibull distribution based on censored samples. J Appl Sci Res 8: 390-400.

MAHMOUD MRAND MANDOUH RM. 2012b. Maximum likelihood estimation of two unknown parameter of beta-Weibull distribution under type II censored samples. Appl Math Sci 6: 2369-2384.

MAHMOUd MR AND MANDOUH RM. 2012c. Maximum likelihood estimation of three unknown parameter of beta-Weibull distribution under type II censored samples. J Appl Sci Res 8: 2221-2231.

MAHMOUDI E. 2011. The beta generalized Pareto distribution with application to lifetime data. Math Comput Simulation 81: $2414-2430$.

MAMELI V. 2012. Two Generalizations of the Skew-Normal Distribution and Two Variantsv of McCarthy's Theorem. Ph.D. Thesis, Università Degli Studi de Cagliari, Italy. (Unpublished).

MAMELI V AND MUSiO M. 2013. A generalizations of the skew-normal distribution: The beta skew-normal. Commun Statist Theor Meth 42: 2229-2244.

MAnsoor M. 2013. Properties and Extensions of Stoppa Income Size Distribution. M.Phil. Thesis, Department of Statistics, The Islamia University of Bahawalpur, Pakistan. (Unpublished). 
Marciano FWP, NAscimento ADC, SAntos-Neto M AND CoRdeIRo GM. 2012. The Mc- $\Gamma$ distribution and its properties: An application in reliability data. Int J Probab Statist 1: 53-71.

MARSHALl A AND OLKIN I. 1997. A new method for adding a parameter to a family of distributions with applications to the exponential and Weibull families. Biometrika 84: 641-652.

Martínez-Florez G, Moreno-Arenas G and Vergara-Cardozo S. 2013. Properties and inference for proportional hazard models. Colombian J Statist 36: 95-114.

MARWA AA, ZAHER H AND ELSHERPIENY EA. 2013. Optimum group limits for maximum likelihood estimation of the exponentiated Fréchet distribution based on grouped data. British J Appl Sci Technol 3: 1464-1480.

MASWADAH M. 2013. On the product and ratio of two generalized order statistics from the generalized Burr type-XII distribution. J Math Statist 9: 129-136.

Maynard J. 2003. A Class of Beta-Exponential Distributions: Properties, Estimation and Applications. Ph.D. Thesis, Central Michigan University, Mount Pleasant, Michigan, USA. (Unpublished).

MAZUCheli J, COELHO-BARRos EA AND ACHCAR JA. 2012. Inferences for the changepoint of the exponentiated Weibull hazard function. REVSTAT 10: 309-322.

MCDONALD JB. 1984. Some generalized functions for the size distribution of income. Econometrica 52: 647-663.

MCDONALD JB AND XU YJ. 1995. A generalization of the beta distribution with applications. J Econometrics 66: $133-152$.

MDZINISO NC. 2012. The Quotient of the Beta-Weibull Distribution. M.A. Thesis, Marshall University, USA. (Unpublished).

Merovei F And Elbatal I. 2013. The McDonald modified Weibull distribution: Properties and applications. Available online from http://arxiv.org/pdf/1309.2961v1.pdf.

Morais AL. 2009. A Class of Generalized Beta Distributions, Pareto Power Series and Weibull Power Series. M.A. Statistics Thesis, Universidade Federal de Pernambuco, Brazil. (Unpublished).

Morais AL, Cordeiro GM And CySneIros AHMA. 2013. The beta generalized logistic distribution. Braz J Probab Statist 27: 185-200.

MUdHOLKAR GS AND HUTSON AD. 1996. The exponentiated Weibull family: Some properties and a flood data application. Commun Statist Theor Meth 25: 3059-3083.

MUdHOLKAR GS AND SRIVASTAVA DK. 1993. Exponentiated Weibull family for analyzing bathtub failure data. IEEE Trans Reliab 42: 299-302.

Mudholkar GS, Srivastava DK AND Freimer M. 1995. The exponentiated Weibull family: A reanalysis of the bus-motor failure data. Technometrics 37: 436-445.

Muthulakshmi S And SELvi BGG. 2013. Double sampling plan for truncated life test based on Kumaraswamy-log-logistic distribution. IOSR J Math 7: 29-37.

NADARAJAH S. 2005a. Exponentiated Pareto distribution. Statistics 39: 225-260.

NADARAJAH S. 2005b. Exponentiated beta distribution. Comput Math Appl 49: 1029-1035.

NADARAJAH S. 2006. The exponentiated Gumbel distribution with climate application. Environmetrics 17:13-23.

NADARAJAH S. 2011. The exponentiated exponential distribution: A survey. AStA Adv Stat Anal 95: 219-251.

NADARAJAH S. 2015a. Newdistns: An R package for new families of distributions. Jnl Stat Soft. To appear.

NADARAJAH S. 2015b. Newdistns: An R package. Available online from http://cran.rproject.org/web/packages/Newdistns/ Newdistns.pdf.

NADARAJAh S, BaKouch HS AND TAHMASBI R. 2011. A generalized Lindley distribution. Sankhyā B 73: 331-359.

Nadarajah S, CANChO VG And OrTega EMM. 2013a. The geometric exponential Poisson distribution. Stat Methods Appl 22: 355-380.

NAdARAJAh S, Cordeiro GM AND ORTEGa EMM. 2012a. General results for the Kumaraswamy G distribution. J Stat Comput Simul 87: 951-979.

NAdARAJAh S, Cordeiro GM AND ORTEGa EMM. 2012b. Some general results for the beta-modified Weibull distribution. J Stat Comput Simul 81: 1211-1232.

Nadarajah S, Cordeiro GM and Ortega EMM. 2013b. The exponentiated Weibull distribution: A survey. Stat Pap 54: 839-877.

Nadarajah S, Cordeiro GM and OrTEga EMM. 2015. The Zografos-Balakrishnan G family of distributions: Mathematical properties and applications. Commun Statist Theor Meth 44: 186-215.

NADARAJAh S AND ElJABRI S. 2013. The Kumaraswamy generalized Pareto distribution. J Data Sci 11: 739-766.

NADARAJAH S AND GUPTA AK. 2004. The beta Fréchet distribution. Far East J Theor Stat 14: 15-24.

NADARAJAH S AND GUPTA AK. 2005. On the moments of the exponentiated Weibull distribution. Commun Statist Theor Meth 34 : 253-256.

NADARAJAH S AND GUPTA AK. 2007. The exponentiated gamma distribution with application to drought data. Calcutta Statist Assoc Bull 59: 29-54. 
NADARAJAh S, JAYAKUMAR K AND Ristic MM. 2013c. A new family of lifetime models. J Stat Comput Simul 83: 1389-1404.

NADARAJAH S AND KotZ S. 2003. The exponentiated Fréchet distribution. InterStat. Available online from interstat.statjournals. net/YEAR/2003/articles/0312001.pdf.

NADARAJAh S AND KotZ S. 2004. The beta Gumbel distribution. Math Probl Eng 4: 323-332.

NADARAJAH S AND KotZ S. 2006a. The exponentiated-type distributions. Acta Appl Math 92: 97-111.

NADARAJAH S AND KotZ S. 2006b. The beta exponential distribution. Reliab Eng Syst Safety 91: 689-697.

Nadarajah S, Nassiri V and Mohammadpour A. 2014a. Truncated-exponential skew-symmetric distributions. Statistics 48: 872-895.

NADARAJah S, Teimouri M and ShiH SH. 2014b. Modified beta distributions. Sankhyā B 76: 19-48.

NAIK SR, Jose KK AND RistiĆ MM. 2008. Semi q-Weibull distributions and autoregressive processes. STARS Int J 2: 139-152.

NANDA AK AND DAS S. 2012. Stochastic orders of the Marshall-Olkin extended distribution. Statist Probab Lett 82: 295-302.

NAsSar MM And EISSA FH. 2003. On the exponentiated Weibull distribution. Commun Statist Theor Meth 32: $1317-1336$.

NASSAR MM AND NADA NK. 2011. The beta generalized Pareto distribution. J Statist Adv Theor Appl 6: 1-17.

Oluyede BO And RajasooriYa S. 2013. The Mc-Dagum distribution and its applications. Asian J Math Appl 2013: Article ID ama0085.

PAL M, Ali MM AND Woo J. 2006. Exponentiated Weibull distribution. Statistica LXVI: 139-147.

Paranaíba PF, Ortega EMM, Cordeiro GM and PAscoa MAR. 2013. The Kumaraswamy Burr XII distribution: Theory and practice. J Stat Comput Simul 83: 2117-2143.

Paranaíba PF, Ortega EMM, Cordeiro GM AND Pescim RR. 2011. The beta Burr XII distribution with application to lifetime data. Comput Statist Data Anal 55: 1118-1136.

PARIKH RV, GHOSH DK AND MURALIDHARAN K. 2008. On Marshall-Olkin generalized exponential distribution. IAPQR Trans 33: 71-81.

PÉReZ-CASAnY M AND CASEllas A. 2013. Marshall-Olkin extended Zipf distribution. Available from http://arxiv.org/ abs/1304.4540.

PERSSON K AND RYDÉN J. 2010. Exponentiated Gumbel distribution for estimation of return levels of significant wave height. J Environ Statist 1: 1-12.

Pescim RR, CORDEIRo GM, DEMÉTrio CGB, OrTEGA EMM AND NADARAJAH S. 2012. The new class of Kummer beta generalized distributions. SORT 36: 153-180.

PESCIM RR, DEMÉTRIO CGB, CORDEIRO GM, ORTEGA EMM AND URBANO MR. 2010. The beta generalized half-normal distribution. Comput Statist Data Anal 54: 945-957.

PILlaI RN. 1985. Semi- $\alpha$-Laplace distributions. Commun Statist Theor Meth 14: 991-1000.

Pillai RN. 1991. Semi-Pareto processes. J Appl Probab 28: 461-465.

PILLAI RN, JOSE KK AND JAYAKUMAR J. 1995. Autoregressive minification processes and the class of distributions of universal geometric minima. J Indian Statist Assoc 33: 53-61.

PUSHKARNA N, SARAN J AND TIWARI R. 2013. Bonferroni and Gini indices and recurrence relations for moments of progressive type-II right censored order statistics from Marshall-Olkin exponential distribution. J Stat Theor Appl 12: 306-320.

QIAN L. 2012. The Fisher information matrix for the three-parameter exponentiated Weibull distribution under type II censoring. Stat Methodol 9: 320-329.

RAJA TA AND MIR AH. 2011. On extensions of some exponentiated distributions with application. Int J Contemp Math Sci 6: $393-400$.

RAJASOORIYA S. 2013. Statistical Properties of the Mc-Dagum Distribution and Related Distributions. M.S. Thesis, Georgia Southern University, Statesboro, Georgia, USA. (Unpublished).

RAO GS, GHITANY ME AND KANTAM RLL. 2011. An economic test reliability plan for Marshall-Olkin extended exponential distribution. Appl Math Sci 5: 103-112.

RAO GS, KANTAM RRL, ROSAIAH K AND PARSAD SVSVSV. 2012. Reliability test plans for type-II exponentiated log-logistic distribution. J Reliab Stat Stud 5: 55-64.

RaO GS, Rosaiah K, KANTAM RRL AND PARSAD SVSVSV. 2013. An economic reliability test plan for generalized log-logistic distribution. Int J Eng Appl Sci 3: 61-68.

RAQAB M. 1998. Order statistics from the Burr type X model. Comput Math Appl 36: 111-120.

RAQAB M AND Kundu D. 2006. Burr type X distribution: Revisited. J Probab Stat Sci 4: 179-193.

RAQAB M AND MADI MT. 2009. Bayesian analysis for the exponentiated Rayleigh distribution. Metron LXVII: 269-288.

RAQAB M AND MADI MT 2011. Inference for the generalized Rayleigh distribution based on progressively censored data. J Statist Plann Infer 141: 3313-3322.

RĚGo LC, CINTRA RJ AND CORDEIRO GM. 2012. On some properties of beta normal distribution. Commun Statist Theor Meth 41: 3722-3738. 
Ristić MM AND BALAKRISHNAN N. 2012. The gamma-exponentiated exponential distribution. J Stat Comput Simul 82: 1191-1206. RistiĆ MM, Jose KK AND JOSEPH A. 2007. A Marshall-Olkin gamma distribution and minification processes. STARS Int J 1: 11-21. Ristić MM AND NADARAJAH S. 2014. A new lifetime distribution. J Stat Comput Simul 84: 135-150.

ROSAIAH K, KANTAM RRL AND KUMAR ChS. 2006. Reliability test plans for exponentiated log-logistic distribution. Econ Qual Control 21: 279-289.

SALAH MM. 2012. Moments from progressive type-II censored data of Marshall-Olkin exponential distribution. Int J Appl Math Res. 1: 771-786.

SALAH MM, RAQAB MZ and AHSANUlLaH M. 2009. Marshall-Olkin exponential distribution: Moments of order statistics. J Appl Statist Sci 17: 91-92.

SALEEM AM AND ABO-KASEM OE. 2011. Estimation for the parameters of the exponentiated Weibull distribution based on progressive hybrid censored samples. Int J Contemp Math Sci 6: 1713-1724.

SARABIA JM AND CASTILlo E. 2005. About a class of maximum stable families with applications to income distributions. Metron LXIII: 505-527.

SARHAN AM, AHMED AEB AND AlAsBAHI IA. 2013. Exponentiated generalized linear exponential distribution. Appl Math Model 37: 2838-2849.

SARHAn AM And Apaloo J. 2013. Exponentiated modified Weibull extension distribution. Reliab Eng Syst Safety 112: 137-144.

Saulo H, LeÃo J and Bourguignion M. 2012. The Kumaraswamy Birnbaum-Sanders distribution. J Stat Theory Pract 6: 754-759.

Shahbaz MQ, Shahbaz S AND ButT NS. 2012. The Kumaraswamy inverse-Weibull distribution. Pakistan J Statist Oper Res 8: 479-489.

Shakil M AND AhSANUllah M. 2012. Review on order statistics and record values from Fa-distributions. Pakistan J Statist Oper Res 8: 101-120.

SHAMS TM. 2013. The Kumaraswamy-generalized Lomax distribution. Middle-East J Sci Res 17: 641-646.

SHAW WT AND BUCKLEY IRC. 2007. The alchemy of probability distributions: Beyond Gram-Charlier expansions, and a skewkurtotic-normal distribution from a rank transmutation map. Research report, Department of Mathematics, King's College London, UK.

SHAwKy AI AND ABU-ZinAdAH HH. 2009. Exponentiated Pareto distribution: Different methods of estimation. Int J Contemp Math Sci 4: 677-693.

SHAWKY AI AND BAKOBAN RA. 2008. Bayesian and non-Bayesian estimations on the exponentiated gamma distribution. Appl Math Sci 2: 2521-2530.

SHAWKY AI AND BAKOBAN RA. 2009. Order statistics from exponentiated gamma distribution and associated inference. Int J Contemp Math Sci 4: 71-91.

SHAWKY AI AND BAKOBAN RA. 2012. Exponentiated gamma distribution: Different methods of estimation. J Appl Math $2012: 23$. SHIRKE DT AND KAKADE CS. 2006. On exponentiated log-normal distribution. Int J Agric Stat Sci 2: 319-326.

SHIRKE DT AND KAKADE CS. 2007. Some inferences on exponentiated Gumbel distribution. Int J Agric Stat Sci 3: 92-106.

SHITTU OI AND AdEPOJU KA. 2013. On the beta-Nakagami distribution. Prog Appl Math 5: 49-58.

SiLVA GO, ORTEGA EMM AND CORDEIRO GM. 2010. The beta modified Weibull distribution. Lifetime Data Anal 16: 409-430.

SINGH U, GUPTA PK AND UPADHYAY SK. 2005. Estimation of parameters for the exponentiated-Weibull family under type-II censoring scheme. Comput Statist Data Anal 48: 509-523.

Singla N, JAIN K AND SHARMA SK. 2012. The beta generalized Weibull distribution: Properties and applications. Reliab Eng Syst Safety 102: 5-15.

SRIVASTAVA AK AND KUMAR V. 2011. Software reliability data analysis with Marshall-Olkin extended Weibull model using MCMC method for non-informative set of priors. Int J Comput Appl 18: 31-39.

Sun J. 2011. Statistical Properties of Convoluted Beta-Weibull Distribution. M.A. Thesis, Marshall University, USA. (Unpublished). Surles JG AND PADGeTt WJ. 1998. Inference for $\mathrm{P}(\mathrm{Y}<\mathrm{X})$ in the Burr type X model. J Appl Statist Sci 7: 225-238.

SURLES JG AND PADGETT WJ. 2001. Inference for reliability and stress-strength for a scaled Burr type X distribution. Lifetime Data Anal 7: 187-200.

SuRLES JG AND PADGETT WJ. 2005. Some properties of scaled Burr type X distribution. J Stat Plann Infer 128: 271-280.

TAVARES LV. 1980. An exponential Markovian stationary process. J Appl Probab 17: 1117-1120.

ThOMAS A AND Jose KK. 2005. Marshall-Olkin semi-Weibull minification processes. Recent Adv Stat Theor Appl 1: 6-17.

TORABI H AND MONTAZARI NH. 2012. The gamma-uniform distribution and its application. Kybernetika 48: 16-30.

TORABI H AND MONTAZARI NH. 2014. The logistic-uniform distribution and its application. Commun Statist Simul Comput 43: 2551-2569.

VENKATESAN P AND SUNDARAM N. 2011. Exponentiated exponential models for survival data. Indian J Sci Technol 4: $923-930$. 
VERHULST PF. 1838. Notice sur la loi la population suit dans son accroissement. Correspondence mathematique et physique, publiee L. A. J. Quetelet 10: 113-121.

VERHULST PF. 1845. Recherches mathematiques sur la loi-d'-accroissement de la population. Nouvelles Memoires de l'Academie Royale des Sciencs et Belles-Lettres de Bruxelles [Memoires, Series 2] 18: 38.

VERHULST PF. 1847. Deuxieme memoire sur la loi d'accroissement de la population. Memoires de l'Academie Royale des Sciences, des Lettres et des Beaux-Arts de Belgique [Series 2] 20: 32.

YANG T. 2012. Statistical Properties of Kumaraswamy Generalized Inverse Weibull Distribution. M.Sc. Thesis, Georgia Southern University, USA. (Unpublished).

YeH HC, ARNOLD BC AND RoBERTSON CA. 1988. Pareto processes. J Appl Probab 25: 291-301.

Zea LM, Silva RB, Bourguignion M, SAntos AM And Cordeiro GM. 2012. The beta exponentiated Pareto distribution with application to bladder cancer susceptibility. Int J Statist Probab 1: 8-19.

ZHANG T AND XIE M. 2007. Failure data analysis with extended Weibull distribution. Commun Statist Simul Comput 36: $579-592$.

ZOGRAFOS K. 2008. On some beta generating distributions and their maximum entropy characterization: The beta-Weibull distribution. In: Barnett NS and Dragomir SS (Eds), Advances in Inequalities from Probability Theory and Statistics, Nova Science Publishers, pp. 237-260.

ZoGRAFOS K. 2011. Generalized beta generated-II distributions. In: Pardo L, Balakrishnan N and Gil MA (Eds), Modern Mathematical Tools and Techniques in Capturing Complexity, Springer, p. 141-153.

ZOGRAFOS K AND BALAKRISHNAN N. 2009. On families of beta- and generalized gammagenerated distributions and associated inference. Stat Methodol 6: 344-362.

Zubair M. 2013. Properties and Extensions of Fisk Income Size Distribution. M.Phil. Thesis, Department of Statistics, The Islamia University of Bahawalpur, Pakistan. (Unpublished). 